IZA DP No. 5645

Women and Power:

Unwilling, Ineffective, or Held Back?

Pablo Casas-Arce

Albert Saiz

April 2011 


\title{
Women and Power: Unwilling, Ineffective, or Held Back?
}

\author{
Pablo Casas-Arce \\ Universitat Pompeu Fabra, Barcelona GSE \\ and SP-SP, IESE Business School
}

Albert Saiz

University of Pennsylvania

and IZA

\section{Discussion Paper No. 5645 \\ April 2011}

IZA

P.O. Box 7240

53072 Bonn

Germany

Phone: +49-228-3894-0

Fax: +49-228-3894-180

E-mail: iza@iza.org

Any opinions expressed here are those of the author(s) and not those of IZA. Research published in this series may include views on policy, but the institute itself takes no institutional policy positions.

The Institute for the Study of Labor (IZA) in Bonn is a local and virtual international research center and a place of communication between science, politics and business. IZA is an independent nonprofit organization supported by Deutsche Post Foundation. The center is associated with the University of Bonn and offers a stimulating research environment through its international network, workshops and conferences, data service, project support, research visits and doctoral program. IZA engages in (i) original and internationally competitive research in all fields of labor economics, (ii) development of policy concepts, and (iii) dissemination of research results and concepts to the interested public.

IZA Discussion Papers often represent preliminary work and are circulated to encourage discussion. Citation of such a paper should account for its provisional character. A revised version may be available directly from the author. 
IZA Discussion Paper No. 5645

April 2011

\section{ABSTRACT}

\section{Women and Power: Unwilling, Ineffective, or Held Back?*}

We develop a model that nests previous explanations for women under-representation in positions of power. Focusing on democratic electoral dynamics, our framework delineates the three types of mechanisms that may be at play: consumer demand, candidate supply, and internal party dynamics beyond electoral markets. We use Spain's Equality Law, requiring a 40 percent female quota in electoral lists, to test the alternative theories. The law was enacted by the social-democratic party after the surprise parliamentary electoral results following the Madrid terrorist bombings, and was therefore completely unexpected by regional political machines. The law only applied to towns with populations above 5000 , so we can use a treatment-control, before-and-after discontinuity design to learn about the impact of female politicians in local elections. Our evidence is most consistent with the existence of entrenched male-dominated political machines capturing influential power positions within the parties.

JEL Classification: J16, J71

Keywords: female political representation

Corresponding author:

Albert Saiz

The Wharton School

University of Pennsylvania

Steinberg-Dietrich Hall, Suite 1466

3620 Locust Walk

Philadelphia, PA 19104-6302

USA

E-mail: saiz@wharton.upenn.edu

\footnotetext{
${ }^{*}$ We thank seminar participants at IESE, Universitat Pompeu Fabra, and the AEDE 2010 meetings for their thoughtful comments. Casas-Arce acknowledges support from the Ministerio de Ciencia y Tecnología (SEJ2007-64340). Saiz acknowledges assistance from the Wharton Global Initiatives Fund.
} 


\section{Introduction}

Over the world, males are largely over-represented in powerful positions in either the public or the private arenas. Only 17 percent of the members of the US Congress and Senate, for instance, are women. Several reasons may explain why women do not reach influential positions more often. Women may be discriminated against by insiders occupying powerful positions, which historically have been men. Women may have a preference for alternative occupations that offer a better balance between professional and personal life. Additionally, in the case of political representation, voters may have preferences for male representatives. Parties would therefore rationally respond to this bias by fielding fewer women candidates.

We argue that it is possible to test among these hypotheses by looking at the effects of introducing female candidate quotas. When party political machines do not discriminate against women they choose their candidates to maximize electoral results. We would only observe fewer women than men if either there are not enough potential female candidates, or if their voters prefer male politicians. Hence, any constraint imposed by female quotas on the party's selection of candidates must result in worse electoral outcomes, either because not enough talented women are available to fulfill the quota, or because voters dislike having more women. In contrast, when party machines discriminate against women, they nominate fewer women than would be optimal at the expense of better electoral results. As a result, female quotas should increase the voting shares of parties that were fielding less female candidates.

We exploit an exogenous change in electoral rules to test the implications of the different theories of female under-representation. Spain's Equality Law offers us an unparalleled opportunity to learn about these issues. The law was passed in 2007 to promote the equality between men and women. The passage of the law (an indirect effect of the Madrid terrorist bombings) had been completely unanticipated by local political machines, candidates, and voters. It required political parties to field candidate lists for local elections with a minimum 40 percent of female candidates. ${ }^{1}$ However, the quotas only applied to municipalities with more than 5000 inhabitants. Using a regression discontinuity design, we can control for factors that differed across municipalities and that changed from one election year to another, such as voters' preferences or attitudes towards women. We focus on all electoral lists and outcomes in both the elections prior to the law (2003) and after (2007).

We find that the law effectively increased the presence of women in the lists by 8 percentage points in the treated municipalities with respect to the counterfactual. This represented

\footnotetext{
${ }^{1}$ The election of town councilors in Spain is done using closed lists, where each list must contain a number of candidates equal to the council seats that are being contended.
} 
an increase of 25 percent in the number of female candidates. Moreover, the law forced parties to maintain the same minimum of 40 percent of women on every five-position bracket of the list. As a result, the number of women on the top 5 positions also increased by a similar amount.

Voter turnout in the municipalities affected by the law was not reduced as a result of the larger number of additional women candidates. This was true regardless of the magnitude of the local change in the share of female candidates, which depended on the average distance to the 40 percent quota in the pre-treatment elections. The number of null or blank votes, which could be thought of as protest votes, measuring disapproval of the political system, was not affected either. These results are not consistent with the existence of major voter aversion to female candidates.

Moreover, there was significant heterogeneity in the initial number of women by list and municipality. A priori, this fact could have been interpreted as signaling the presence of gender preferences among voters that are correlated with ideology (e.g. conservative voters in rural areas may have different tastes). However, we find that parties that were "forced" to make larger increases in the number of female candidates improved their electoral performance relative to the other parties. Thus the evidence is not consistent with the existence of voter-specific tastes against female candidates. On the contrary, at the margin, voters seemed to be happier with more balanced lists, suggesting that parties were not optimizing the gender composition of their lists prior to the law. This is an important result in the context of the conflicting existing research of the impact of women on electoral outcomes. Papers based on voter surveys in the US claim to find evidence of voter discrimination but correlational evidence suggests a neutral or positive impact of female politicians on electoral outcomes (Dolan, 2004, 2005). In this context, we provide evidence of a positive impact of women politicians using a clean quasi-experimental design that exogenously increased the number of female candidates in a treatment group of municipalities, but did not in a similar control group.

We further find, as the party discrimination theory predicts, that the positive effect of women on votes was concentrated in municipalities with non-competitive elections, where one party had enjoyed an absolute majority in the 2003 elections. Consistent with this finding, women had been more severely underrepresented in the "safer" seats of incumbent parties in these uncompetitive environments prior to the law.

We also show that parties did not have major problems finding suitable female candidates to fill in the quotas. The Equality Law was not associated with increased list attrition or difficulties for new lists to arise. Parties did not need to retain past female candidates more often or to promote female "filler" candidates to top positions either. Together with the 
results on electoral outcomes, this evidence is not consistent with the existence of major supply constraints of high-quality female candidates.

These results do not seem to be driven by women's lack of a desire to compete for a position in the list. While women may shy away from competition on average, a large number of women in competitive lists leveraged the quota to attain higher positions than the minimum ones guaranteed by the law. This evidence is not consistent with generalized female preferences for lower spots in the lists. The evidence seems most consistent with the existence of entrenched male-dominated political machines, especially in less competitive environments.

Finally, we find that discrimination against females by party machines had not impacted disproportionally the supply of highly-qualified female candidates. Names and surnames are quite informative of educational and socioeconomic status in Spain. However, the new women attracted by the quotas were not on average of higher socioeconomic backgrounds, as captured by their names.

The paper contributes to an extensive literature on discrimination in labor markets (Becker, 1957). There is clear evidence of gender discrimination in hiring (Goldin and Rouse, 2000), and product markets (Ayres and Siegelman, 1995). A related literature on ethnic discrimination has studied market-driven preferences for segregation (see Saiz and Wachter, 2011, for a recent example and references therein) and in other less conventional environments (Kahn, 1991; Szymaski, 2000; Price and Wolfers, 2010). Municipal elections allow us to study a very relevant setting, yet one where a very good performance measure is available: electoral results. Moreover, because quotas were unexpected and only imposed on some municipalities, we have an essentially random selection of treated and untreated municipalities, that allows us to eliminate the effects of potentially confounding factors.

Our paper complements previous evidence about the importance of internal political machines to account for female under-representation. Sanbonmatsu (2002) finds that women are less likely to be represented in US state legislatures where parties have more control over nominations. Bagues and Esteve-Volart (2009) show that parties place female candidates strategically in the positions that are less likely to affect the chances of election of male candidates. The paper also relates, somewhat distantly, to a large recent literature on the policy effects of females in power (e.g. Chattopadhyay and Duflo, 2004; Beaman et al., 2009). ${ }^{2}$ This literature has focused mainly on the policy outcomes of female elected

\footnotetext{
${ }^{2}$ The literature on the impact of women in power on parliamentary votes, budget levels, budget composition, government stability, and government efficiency is now quite large. Note that we do not have much to contribute to this specific literature, since we are not examining the policy impact of the additional elected women due to the quota., Instead, we use the natural experiment to learn about the causes of female underrepresentation in the lists. For the reader interested on women politicians and outcomes, other examples
} 
leaders, effects of quotas on the number of elected females, or the change in attitudes towards women once they are elected, and not on the intrinsic causes that account for women underrepresentation.

Finally, the paper is related to an emerging literature that tries to explain gender inequality. Several explanations have been proposed, such as the existence of differences in gender attitudes towards competition (Gneezy and Rustichini, 2004; Gneezy et al., 2003). These theories are focused on explaining why the average woman may be less likely to seek powerful positions; however, they cannot by themselves account for the lack of women at the top since, in a competitive environment, there could be enough available women at the right tails of the ambition-ability joint distribution to satisfy hypothetical customer demand for more balanced gender allocations in the relatively few powerful positions. As we argue using an electoral model, we will not be able to fully understand female under-representation in positions of power unless we consider the interaction between the demand-side in political markets (voter preferences), the marginal supply of qualified female inputs at the tails of the ability distribution, and the industrial organization of the market (the role of parties and the degree of electoral competition).

The paper proceeds as follows. In section 2 we describe the Spanish municipal elections and their 2007 reform. In section 3 we develop a simple model of electoral competition that nests the theories that can potentially explain low female representation. The model illustrates what each of these theories predicts the effects of the electoral reform should be. Section 4 describes the data that we use to test the different theories, and section 5 explains the results. Some alternative explanations are assessed in section 6 . We offer some concluding remarks in section 7.

\section{Municipal Elections and Electoral Reform}

The election of town councilors in Spain is done using closed lists. This means that voters vote for a list, rather than a person. Each list must present a number of candidates equal to the number of council seats at stake (11 for municipalities between 2,000 and 5,000 inhabitants; 13 for municipalities between 5,000 and 10,000). A large number of lists concur under the umbrella of national or regional political parties, albeit the existence of local independent lists is not uncommon. Voters vote for the lists as a whole, and the council seats are apportioned proportionally to the number of votes according to the d'Hont method. The

of this burgeoning literature include: Welch (1985), Swers (1998), Rehavi (2007), Clots-Figueras (2009), Funk and Gathman (2010), De Paola et al. (2010), Gallarduci and Passerman (2010), Ferreyra and Gyourko (2010), Cavalcanti and Tavares (2011). Campa (2010) studies the impact of quotas in Spain on the provision of childcare. 
law, however, establishes a minimum vote threshold of $5 \%$ in order for a list to qualify for the apportionment of council seats. The council members are then drawn from each list using the exact ordering in which the candidates appear listed.

Upon convening for the first time, the council elects a mayor, typically the first person in the most-voted list. Importantly, only the first person in each list can be considered in the initial mayoral vote. The council also acts as a representative legislative body passing and enacting all local budgets, laws, regulations, and tax codes for a period of four years.

On March 22, 2007, the "Law for the equality of women and men" was passed by the Parliament. ${ }^{3}$ It required all candidate lists for the municipal (and other) elections to contain at least 40 percent of candidates of each gender. Moreover, in order to prevent parties from placing all women at the bottom of the list, the law required this proportion to be maintained for every bracket of five positions. Nevertheless, the law specified an exception to the quota in those municipalities with fewer than 5,000 inhabitants.

The law applied for the first time to the municipal elections that followed on May 27, 2007. In the previous election of May 25, 2003, no such legal change had been contemplated. Indeed, the passing of the law was made possible by the results of the 2004 general election, which were largely unanticipated (Montalvo, 2009). Only days before the Madrid train bombings of March 11th 2004 the Christian-Democratic Party (PP) was widely expected to win the elections. The bombings and post-attack management from the incumbent party changed the sentiment of many voters towards the Social-Democratic party (PSOE), which won the elections four days after the terrorist strike. It is therefore quite unlikely that the share of female candidates in the municipal elections of 2003 reflected an anticipation of the female quotas that were imposed in 2007.

\section{Female Representation and Quotas: A Comprehensive Framework}

There are several reasons why the number of women in powerful positions may be low. First, political parties may behave as if they were discriminating against women by fielding less women in electable positions (Sanbonmatsu, 2002, 2006; Bagues and Esteve-Volart, 2009). This could be due to (traditionally male) powerful elites explicitly failing to promote women. Alternatively it could be due to internal organizational dynamics that implicitly favor men (Reuben et al., 2010), or by the desire of women to avoid competition (Gneezy et al., 2003, Niederle and Vesterlun, 2007) for power within the parties (non-adversarial behavior within

\footnotetext{
${ }^{3}$ This law has a broad reach, affecting both the public and private sectors. But we describe here only the implications for the municipal elections that we study in this paper.
} 
organizations). All these explanations can be encompassed under what we name the "party discrimination theory."

A second reason for observing low female participation resides in the tastes of voters. As long as voters prefer to be governed by men, political parties will rationally respond by restricting access to women. They will do so in order to increase the chances of winning, even if the parties themselves do not have a taste for discrimination. We call it the "voter preference theory." Duflo and Topalova (2004) and Beaman et al (2009) find evidence that male voters in India report preferring male politicians. However, they also find that discriminatory preferences dissipate with better knowledge of the candidate. These are important contributions in the context of villages in a developing country with very large social stratification. Nevertheless less is known about effective voting preferences for women candidates in more developed countries, with existing research in political science providing arguments on both sides based on correlational and survey evidence (see Dolan, 2004, 2005, for a US-based discussion).

Finally, low female participation may also be the result of self-selection into political activities leaving parties with a worse pool of female contenders. This explanation is related to statistical discrimination theories (Arrow, 1973, and Knowles et al., 2001). Potential female candidates may be less able than male contenders if politics is inherently more com-

petitive, and women shy away from competitive environments (non-adversarial behavior in open markets). Talented women may also avoid a career in politics if such jobs offer a worse family-life balance than other alternatives (Lawless and Fox, 2005; Goldin and Katz, 2008; Bertrand et al., 2010). In general, as documented by Crosson and Gneezy (2008), there are a number of psychological differences between genders that could have high-ability females see themselves as less suitable politicians (Lawless and Fox, 2005). We term this explanation the "self-selection theory."

In this section we develop a theoretical framework that encompasses these three theories of low female representation. The model highlights the different predictions that the three theories make about the effects of imposing female quotas on parties' lists. These predictions will help us discern among the empirical validity of the different theories. The model is also helpful as an intellectual placeholder that consolidates the ideas in what is a very diverse literature on women in power.

\subsection{The Setup}

Consider two parties located at the extremes of the interval $[0,1]$. Each party must choose a continuum of candidates with a mass of 1 . The fraction of candidates that are elected from 
this list is determined by the fraction of votes that each party gets.

There is a continuum of voters located uniformly on $[0,1]$. Their location on the line represents their policy preferences. Voters care for the policies of the parties, for the average competence of their candidates, and the share of women on their lists. We represent the preferences of a voter located in $x \in[0,1]$ as: $u(x, p)=v-\frac{t}{2}|p-x|+A_{p}-d_{v}(x) W_{p}$, where $u(x, p)$ represents the utility from voting for the party located in $p \in\{0,1\}$. The term $-\frac{t}{2}|p-x|$ captures the disutility from voting a party whose policy $p$ differs from the preferred policy $x$. The parameter $t$ measures the degree of competition among the two parties (how substitutable they are for voters). $A_{p}$ is the average ability of party $p$ 's candidates, and $W_{p}$ is the share of women on its list. The parameter $d_{v}(x) \geq 0$ measures voter $x$ 's distaste for voting for female candidates. We assume that $d_{v}(x)$ is a monotonic function, and satisfies $\left|d_{v}^{\prime}(\bar{x})\right|<\kappa \leq 1$ for all $x \in[0,1] .{ }^{4}$ Alternatively, a voter may also abstain from voting, and obtain $u(x, \emptyset)=\underline{u}$. This utility can be thought of as the opportunity cost of voting.

We assume that parties cannot choose their ideology and policies (set at the national level) but can choose the identity of their candidates. They do so simultaneously, á la Cournot. Each party has a pool of potential candidates to choose from. Let $f_{p m}$ and $f_{p w}$ be the density functions for the distributions of ability of men and women contenders to become candidates for party $p$. We assume throughout that there exists a constant $a_{p g}$ such that we can write $f_{p g}(x)=f_{g}\left(x-a_{p g}\right)$ for $p \in\{0,1\}, g \in\{m, w\}$ : the distribution of ability is the same for both parties, except for a mean shifter. ${ }^{5}$ We denote the corresponding distribution functions with capital letters.

Parties choose their candidate lists with the objective of maximizing $\pi^{p}=V_{p} /\left(V_{0}+V_{1}\right)-$ $d_{p} W_{p}$, where $V_{p}$ is the number of votes received by party $p$, and $d_{p}$ is the party machine's distaste for having women on its list. Therefore, both parties want to increase their share of the votes, but may also like to decrease the number of women on their list.

Given their preferences, voters located on $\left[0, \bar{x}_{0}\right]$ vote for party 0 , voters located on $\left[\bar{x}_{1}, 1\right]$ vote for party 1 , and voters located on $\left(\bar{x}_{0}, \bar{x}_{1}\right)$ abstain, where $\bar{x}_{p}$ denotes the marginal voter of party $p .{ }^{6}$ Hence, we have that $V_{0}=\bar{x}_{0}$ and $V_{1}=1-\bar{x}_{1}$. Notice that when no voter abstains, the marginal voters of both parties coincide, and we will write $\bar{x}=\bar{x}_{0}=\bar{x}_{1}$.

\footnotetext{
${ }^{4}$ As will become clear later, to fully comprehend the empirical evidence, it is important to have heterogeneity in the voters' preferences for discrimination, and this heterogeneity being correlated with the preferences for the parties. On the other hand, assuming that $d_{v}^{\prime}(\bar{x})$ is not too large (in absolute terms) guarantees that the parties' objective function is well behaved.

${ }^{5}$ This encompasses, for instance, the case in which ability is normally distributed with the same variance $\sigma^{2}$ for all parties and genders, while the mean may vary by party and gender. The assumption also allows the variance to vary by gender, as long as for each gender both parties have the same variance.

${ }^{6}$ This result follows from the assumption that $\left|d_{v}^{\prime}(\bar{x})\right|<1$, that guarantees that the voters' preference over the location of the parties dominates the preference over the number of women.
} 
This model captures with simplicity the three theories described above. The party discrimination theory states that $d_{p}>0$. Under the voter discrimination theory, $d_{v}(x)>0$. And finally, the selection theory can be captured by the difference between $f_{p w}$ and $f_{p m}$. In the following section we describe the implications of these theories for the selection of candidates.

\subsection{The Economics of Gender Selection}

For a given share of women, parties are interested in maximizing the average ability of their candidates. They will consequently choose the best male and female candidates among the pool of contenders of each gender. Therefore, parties optimally set standards $\underline{a}_{p m}$ and $\underline{a}_{p w}$ such that $p$ 's list contains all male contenders with $a \geq \underline{a}_{p m}$ and all female contenders with $a \geq \underline{a}_{p w}$. As a result, we have

$$
A_{p}=\int_{\underline{a}_{p m}}^{\infty} a f_{p m}(a) d a+\int_{\underline{a}_{p w}}^{\infty} a f_{p w}(a) d a
$$

and

$$
W_{p}=\int_{\underline{a}_{p w}}^{\infty} f_{p w}(a) d a=1-F_{p w}\left(\underline{a}_{p w}\right)=F_{p m}\left(\underline{a}_{p m}\right),
$$

where the last equality holds because the number of men and women add up to unity. Since lists have a fixed size, determining the standard for women also fixes the standard for men. Indeed, $\frac{d \underline{a}_{p m}}{d \underline{a}_{p w}}=-f_{p w}\left(\underline{a}_{p w}\right) / f_{p m}\left(\underline{a}_{p m}\right)$ and, effectively, party $p$ only has one instrument to maximize its objectives: $\underline{a}_{p w}$.

Consider what happens when $\underline{u}$ is sufficiently low to induce all voters to turn out to vote. The marginal voter is now implicitly defined by the equation: $\bar{x}=\frac{1}{2}+\frac{1}{t}\left[\left(A_{0}-A_{1}\right)-d_{v}(\bar{x})\left(W_{0}-W_{1}\right)\right]$. As a result, party $p$ 's objective is

$$
\max _{\underline{a}_{p w}} V_{p}-d_{p} W_{p}
$$

where $V_{0}=\bar{x}$ and $V_{1}=1-\bar{x}$. The first-order condition for this problem is $\frac{d V_{p}}{d \underline{a}_{p w}}-d_{p} \frac{d W_{p}}{d \underline{a}_{p w}}=0$. Applying the implicit function theorem to the equation that defines $\bar{x}$, and differentiating $A_{p}$ and $W_{p}$ with respect to $\underline{a}_{p w}$, we can write the first-order condition as:

$$
\underline{a}_{p w}-\underline{a}_{p m}=d_{v}(\bar{x})+d_{p}\left[t+d_{v}^{\prime}(\bar{x})\left(W_{0}-W_{1}\right)\right] .
$$

This equation defines the optimal selection policy of party $p$, determining the levels of the ability standards for men and women. ${ }^{7}$

\footnotetext{
${ }^{7}$ The second derivative of the objective function is negative at the optimum when $d_{v}$ is constant. Therefore,
} 
When neither parties nor voters discriminate $d_{v}=d_{p}=0$. In this case, $\underline{a}_{p w}=\underline{a}_{p m}$, so that men and women face the same standard. Parties maximize the average ability of their candidate list, regardless of the gender of the candidates. This, however, does not mean that women share the positions equally with men: more men are chosen on the party's list if they are more politically able than women, and $f_{p m}$ first-order stochastically dominates $f_{p w}$.

When either parties or voters discriminate, the ability standard for women increases while the standard for men is lowered. $d_{v}$ and $d_{p}$ determine then the ability difference that party $p$ requires to accept a women on the list.

To gain some intuition, suppose first that voters discriminate, but parties do not, so that $d_{v}(x)>0$ and $d_{p}=0$. When optimizing the candidate list, parties are actually maximizing the utility of the marginal voter $\bar{x}$. Since voter $\bar{x}$ has a taste for discrimination of $d_{v}(\bar{x})$, this voter is willing to substitute a woman for a man in order to reduce $W_{p}$ as long as the difference in ability between the man and the woman is smaller than $d_{v}(\bar{x})$. Therefore parties targeting this marginal voter choose a list such that: $\underline{a}_{p w}-\underline{a}_{p m}=d_{v}(\bar{x}) .{ }^{8}$ In this list, the ability of the marginal woman exceeds the ability of the marginal man by exactly $d_{v}(\bar{x})$.

On the other hand, suppose that voters do not have discriminatory tastes, but parties do, so that $d_{v}(x)=0$ and $d_{p}>0$. Now the optimal selection policy sets $\underline{a}_{p w}-\underline{a}_{p m}=d_{p} t$. Parties are willing to sacrifice votes in order to decrease the number of women. The benefits for party $p$ from dropping a women from the list, $d_{p}$, has to be weighted against the cost in votes, which depends on the degree of competition $t$. If $t$ is large, the election is less competitive, and the electoral results are less sensitive to the number of women on party $p$ 's list. Hence this party can use a selection policy that is more responsive to its taste for discrimination. On the other hand, if $t$ is low, the contest is very competitive. Voters do not have a strong preference for a party's policy. As a result, voters are more sensitive to the ability of party candidates. A decrease in the quality of candidates results in more votes being lost to the other party. Consequently, parties do not respond so strongly to their preferences for discrimination.

When voters and parties discriminate simultaneously, the differences in qualification standards for men and women reflect the preferences for discrimination of both. Parties can decrease the number of women without cost (indeed, they benefit) as long as their marginal voter demands it. When the difference in standards surpasses $d_{v}(\bar{x})$, increasing $\underline{a}_{p w}-\underline{a}_{p m}$ to reduce the number of women comes at the cost of a loss of votes. As earlier, parties will

there exists a $\kappa>0$ such that the second-order conditions are satisfied as long as $\left|d_{v}^{\prime}(\bar{x})\right|<\kappa$ for all $x \in[0,1]$.

${ }^{8}$ Notice that the optimal selection of candidates follows a marginalist argument: how much more able should the marginal woman be than the marginal man, for a party to stay indifferent. It is therefore not surprising that the optimal policy does not depend on the distribution of talent for men and women. Although the final number of women that will be selected does depend on those distributions. 
still want to do it as long as that cost does not exceed $d_{p}$. The loss of votes still depends on how competitive the election is. But now it also depends on how much preferences for discrimination change as the marginal voter shifts closer to the party's location. This additional effect- $d_{v}^{\prime}(\bar{x})\left(W_{0}-W_{1}\right)$ - is positive for the party with fewer women if its more loyal voters also have a stronger taste for discrimination: this party would find that reducing the number of women has a smaller cost. As the marginal voter gets closer to its location, he discriminates more, and therefore, penalizes the party less for the smaller number of women.

When turnout is lower than $100 \%$, the results are analogous. If $\underline{u}$ is sufficiently high, the voters in intermediate locations abstain. Now, party $p$ 's marginal voter is indifferent between voting that party and abstention. Therefore : $V_{p}=\frac{2}{t}\left[v-\underline{u}+A_{p}-d_{v}\left(\bar{x}_{p}\right) W_{p}\right]$, and party $p$ 's objective is now:

$$
\max _{\underline{a}_{p w}} \frac{V_{p}}{V_{0}+V_{1}}-d_{p} W_{p}
$$

The first-order condition for this problem leads to a similar condition characterizing the optimal policy of party $p$ :

$$
\underline{a}_{p w}-\underline{a}_{p m}=d_{v}\left(\bar{x}_{p}\right)+d_{p} \frac{\left(V_{0}+V_{1}\right)^{2}}{V_{1-p}}\left[\frac{t}{2}+(-1)^{p} d_{v}^{\prime}\left(\bar{x}_{p}\right) W_{p}\right] .
$$

If voters have discriminatory tastes, parties respond by maximizing the preferences of the marginal voter. However, the marginal voter is now different for each party. Hence, parties may select different number of women simply because they are targeting different voters. Likewise, when parties discriminate, the response to their taste for discrimination depends on the competitiveness of the election $t$. However, the size of their constituency now becomes important. To see why, consider what transpires when party $p$ loses one voter. This voter will abstain, instead of voting for the other party, as before. When party $p$ obtains the majority of the votes in the election, any lost vote translates now into a smaller decrease in the list's voting share. ${ }^{9}$ Therefore, the party finds it less costly to discriminate. This effect is analogous to the effect of low competition.

To obtain some intuition for the effects of introducing female quotas, consider first what happens when one party is unilaterally forced to increase the number of women on its list. If this party discriminated against women, the average ability of its candidates will increase, and hence so will voters' preferences for that party. The party's electoral results improve as a result. On the contrary, when voters discriminate, or when female contenders are less talented than male candidates, increasing the number of women decreases the voters' utility

\footnotetext{
${ }^{9}$ Notice that the change in the share of votes of party $p$ due to a change in $V_{p}$, which is given by $V_{1-p} /\left(V_{0}+V_{1}\right)^{2}$, is decreasing in $V_{p}$.
} 
from voting that party, which will obtain worse electoral results.

This intuition suggests testing for the existence of party discrimination by looking at the effects of a forced increase in the number of women. However, in practice, quotas are imposed on all parties. We must therefore take into account the equilibrium implications of imposing quotas on both parties.

\subsection{Equilibrium Effects of Female Quotas}

The effect of imposing female quotas on the candidate lists depends in a systematic way on the parameters $f_{p w}, f_{p m}, d_{v}$, and $d_{p}$. Nevertheless, the three theories of low female participation described above make different predictions about the outcomes.

First, consider the hypothesis of party discrimination. To isolate the effects of this theory, assume that voters do not have a preference for discrimination, and there are no differences in the gender distributions of talent. Under this strong null hypothesis, if party 0 selected fewer women on its list, it must be because it discriminated more $\left(d_{0}>d_{1}\right)$ at the expense of higher candidate abilities. As a result, imposing binding female quotas increases the average ability of its candidates by more than in party 1 . Since voters value the ability of candidates, party 0 becomes more attractive, and gains more votes than party 1 does when quotas are imposed. Indeed, when no voter abstains, party 0 can only gain votes at the expense of party 1 , whose votes are reduced. The effect of quotas on turnout is positive, as long as the outside option of voters is binding, and some of them decide not to vote. Otherwise, turnout remains unaffected. The following proposition summarizes these results:

Proposition 1 (Party discrimination). Suppose that $d_{0}, d_{1}>0$, while $f_{p w}=f_{p m}$ for $p \in$ $\{0,1\}$, and $d_{v}=0$. Suppose also that $W_{0}<W_{1} \leq \frac{1}{2}$ when no female quotas are imposed. Then, introducing a female quota $\underline{W} \in\left[W_{1}, \frac{1}{2}\right]$ (weakly) increases turnout, and increases the number of votes for party 0 by more than for party 1. Indeed, if turnout is $100 \%$ without female quotas, then a female quota decreases the number of votes for party 1.

Proof. See Appendix A.

Note from proposition 1 that the results for one party are always relative to what the other party is doing. If the two parties have the same initial number of women, then quotas have no effects on the electoral results because they affect both parties equally. Only relative increases in the number of women caused by the quota affects positively the electoral results.

If female under-representation was driven by voter discrimination against women, the opposite is true. In this case, parties rationally responded to the voters' taste for discrimination by decreasing the share of women on their lists. Quotas, therefore, decrease the utility of 
voters, and may lead to a decrease in turnout. Moreover, if party 0 starts with a lower share of women it must be because its voters have a stronger preference for discrimination. Their utility would decrease by more than that of party 1's voters for two reasons. First, having a stronger taste for discrimination, party 0's voters suffer more from any given increase in the number of women. Furthermore, because party 0 had fewer women, it is also forced to increase the number of women by more than party 1 . Therefore, quotas will hurt party 0 more, and it will lose more votes than party 1 , as a result. ${ }^{10}$

Proposition 2 (Voter preferences). Suppose that, for all $x, d_{v}(x)>0$ and monotonic, while $f_{p w}=f_{p m}$ for $p \in\{0,1\}$, and $d_{0}=d_{1}=0$. Suppose also that $W_{0}<W_{1} \leq \frac{1}{2}$ when no female quotas are imposed. Then, introducing a quota $\underline{W} \in\left[W_{1}, \frac{1}{2}\right]$ (weakly) decreases turnout, and decreases the number of votes for party 0 by more than for party 1.

Proof. See Appendix A.

Note that the existence of differences in the number of women before the quotas were introduced implies that turnout was less than $100 \%$. Differences in the number of women can only arise when parties target voters with different preferences.

Finally, suppose that women under-representation was not due to parties or voters discriminating against female candidates. In that case, both parties set $\underline{a}_{p w}=\underline{a}_{p m}$. The self-selection hypothesis thus requires $f_{p m}$ to first-order stochastically dominate $f_{p w}$. As a result, the party with the lower number of female candidates must have fewer high ability female contenders, relative to the number of male contenders. Hence, forcing the parties to have an equal number of male and female candidates decreases the average ability of this party's list by more. This theory also predicts that quotas lower turnout, since they decrease the utility of voters.

Proposition 3 (Self-selection). Suppose that $a_{p w}<a_{p m}$ for $p \in\{0,1\}$, while $d_{v}=0$, and $d_{0}=d_{1}=0$. Suppose also that $W_{0}<W_{1} \leq \frac{1}{2}$ when no female quotas are imposed. Then, introducing a quota $\underline{W} \in\left[W_{1}, \frac{1}{2}\right]$ (weakly) decreases turnout, and decreases the number of votes for party 0 by more than for party 1. Indeed, if turnout is $100 \%$ with female quotas, then a female quota increases the number of votes for party 1 .

Proof. See Appendix A.

It is difficult to distinguish the voter-preferences and self-selection theories in the data, as they both make similar predictions. But the party discrimination theory makes opposite claims. Hence, we can test whether parties discriminated against women by looking at the

${ }^{10}$ The monotonicity of $d_{v}(x)$ ensures this is the case. 
effects of the increase in female participation caused by quotas on total voter turnout, and on the share of votes received by a given party. To the extent that parties discriminate, we expect to see a positive effect of an increase in female participation on voter turnout.

The theory also suggests that the variable that determines the change in the performance of a given party is not the absolute increase in its number of women caused by the quota. Instead, it is the relative increase with respect to the other party that is relevant. To the extent that parties discriminated, a relative increase in female participation in a given party will affect positively its performance in the elections. We now take these predictions to the data.

\section{The Data}

The Spanish State Department (Ministerio del Interior) collects information related to the electoral process. On request, we obtained a non-confidential subset of their data. Concretely we were provided with the name of all candidates by list in all municipal ballots in the 2007 and 2003 elections $^{11}$, their gender in 2007 (a disclosure required by the Equality Law), their list affiliation to major parties, information about each individual's position in the lists, and on whether they resulted elected. We also have information about the number of votes for all lists presented, fraction of null or blank votes, the estimated municipal population for legal purposes, and the number of registered voters in each town.

We imputed gender in 2003 by using the first name of the candidate. Names in Spain have very strong gender orientation and only a very small portion of candidates in 2007 had names that could be ascribed to either sex, which made the imputation straightforward.

Since the law applied only to municipalities with more than 5,000 inhabitants, we can only obtain meaningful results around this threshold. Population sizes follow an approximately Pareto distribution, so there is a very large amount of very small municipalities with population in the few hundreds that probably do not provide us with a very good comparison group. In order to ensure both comparability and large enough sample sizes we therefore restrict our sample to those municipalities with populations between 2,000 and 8,000 inhabitants. However, the results are not in the least sensitive to variations in this threshold, as we demonstrate later. We also collected data on unemployment rates (a very good local socioeconomic status indicator in Spain), and other economic characteristics of the towns. These additional characteristics never mattered for any results in the paper and are mostly omitted insofar most specifications include municipal fixed effects. Furthermore, the evidence is consistent with the experimental design: there were no differences in observables on

\footnotetext{
${ }^{11}$ Other characteristics, such as the birth date, have been suppressed from the data for confidentiality.
} 
both sides of the Equality Law discontinuity ${ }^{12}$.

\section{Empirical Evidence}

\subsection{Equality Law and the Surge in Female Politicians}

The legal reform implemented in 2007 required all political parties to present candidate lists containing at least 40 percent of women. However, it is not obvious what the percentage of women politicians would have been in the absence of the quota. In Table 1 we examine nonparametrically whether the law had a real sizable effect on the proportion of women in the candidate lists of the 2007 municipal elections. We do so by presenting transition matrices for repeat lists by number of women in both the 2003 and 2007 elections (pre and post quota). Repeat lists are those that used the same party affiliation in both elections. In fact, 72 percent of party candidatures in 2007 were also present in the previous elections. ${ }^{13}$

It is very clear that the law was binding and that most repeat lists quickly complied with the new legislation. The differences between the control municipalities (with populations between 2,000 and 4,999) and treatment (between 5,000 and 8,000) are stark. The distribution of lists by number of women was quite similar in the 2003 elections. However, almost all candidatures with less than five women in the list in 2003 in the treated municipalities transitioned toward having five or more. The Equality Law allowed for rounding the proportion of women to the closest integer, and thus in order to comply a candidature should have at least 5 women. However, most treated candidatures decided to include at least 6 women, perhaps because of uncertainty about the application of the numerical thresholds. Only $1.13 \%$ of the lists seemed not to fully comply. ${ }^{14}$

In Table 2 we use a regression discontinuity approach to assess the actual average treatment effect of the law on female political participation. This design allows us to use the share of women in the lists of the control municipalities as a counterfactual, and to estimate the average treatment effect of the law on female participation and other outcomes. The regression format also allows us to include all electoral lists by municipality pre and post treatment. In column 1 we start by using only the data from the 2007 elections at the municipal level. The model that we estimate takes the form:

$$
W_{i 07}=\alpha D_{i E L}+P_{d}\left(\gamma^{\prime}, P_{o p} p_{i 07}\right)+\varepsilon_{i 07}
$$

\footnotetext{
${ }^{12}$ Interested reader should see Appendix Table 2

${ }^{13}$ We study patterns of list attrition later, and we will show that list attrition is not a problem in this "repeat sample" estimation.

${ }^{14}$ It is also possible that the gender of some of the candidates may have been recorded with error.
} 
Where the subscript $i$ denotes a municipality; $W_{i 07}$ is the dependent variable of interest: the share of women concurring to the municipal elections in 2007 in each town; $D_{i E L}=0$ if $P_{o p} p_{i 07}<5000$ and $D_{i E L}=1$ if $P o p_{i 07} \geqslant 5000$ is the treatment dummy signifying the local adoption of the Equality Law, Pop $i 07$ is the municipality population in 2007, and $P_{d}\left(\gamma^{\prime}, P_{o p} p_{07}\right)$ is a polynomial of degree $d$ with a vector of parameters $\gamma^{\prime}$ that vary on both sides of the population discontinuity that defines the law (5000 inhabitants). Note that the polynomial on population is fully interacted by the inequality law dummy and different parameters are allowed on both sides of the discontinuity. We choose a functional form where $d=3$, but results are not sensitive at all to our specification of $P_{d}\left(\gamma^{\prime}, P_{o p_{i 07}}\right.$ ) (such as higher order polynomials, including a simple linear population control, or omitting the term in the municipality fixed effects regressions that we finally implement throughout).

The results show a $7.2 \%$ increase in the share of women in the parties' lists for the municipalities that were affected by the law, as compared to unaffected municipalities. The identification strategy is based on the assumption that the share of women politicians in a town may change continuously with respect to population levels, so that any effects associated to moving from a municipality just below 5000 inhabitants to one above are due to the law. In column 2 we show the results to be robust to regional dynamics by including fixed effects for each of the 50 provinces in the country. ${ }^{15}$

We next check if the results could be driven by exogenous factors that change discontinuously when a municipality reaches 5000 inhabitants. First we run a placebo regression for the 2003 elections, where no equality law existed. The results in column 3 yield a very precisely estimated zero, suggesting that the effects in 2007 were driven by the legal change. To control for unobservable variables that differ on both sides of the discontinuity more generally, we next specify empirical models that use both election years: pre and post Equality Law. The equation that we estimate becomes:

$$
W_{i t}=\alpha D_{i E L} \times D_{07}+\pi D_{07}+P_{d}\left(\gamma^{\prime}, P_{o p} p_{i t}\right)+\sum M_{i}+\varepsilon_{i t}
$$

In this equation $t$ is a time subscript ( $\mathrm{t}=03,07), D_{07}$ is a post-treatment dummy (for year 2007). The model is saturated with 1,437 municipal fixed effects $\left(M_{i}\right)$, one for each town in the relevant sample, and all variation is coming from changes within municipalities. The results in column 4 show conclusively that the increase in women politicians was larger in treated municipalities after the treatment. In quantitative terms, treated municipalities saw an increase in 8.5 percentage points in the fraction of women in lists. Since the fraction of

\footnotetext{
${ }^{15}$ In unreported regressions we also controlled for the unemployment rate and other measures of local industrial composition and amenities without any change in the results. None of the controls was significant in explaining women political power.
} 
women in the treated sample was 33 percent before the Equality Law this implies a very large shock to the number of women candidates of 25 percent. ${ }^{16}$

One of the interesting aspects of the Equality Law is that it required the presence of at least two women for every five candidates as ranked in the lists. Thus, parties could not place all women at the bottom of the list. This was quite important for the new women to have chances of being elected. $78.49 \%$ of the lists in the treated interval of municipalities (an average of 3 lists by municipality) obtained 5 seats or less in the 2007 elections. Only 2.5 percent of lists obtained more than eight seats. Therefore, individuals in lower positions in the list of 13 are widely perceived as "token" candidates. We find, in column 5, that the law did have a very similar causal impact in the top 5 positions with respect to the counterfactual. However, in column 6 we also show that the increase in the percentage of elected women was about only half of the magnitude of the increase in women participation. This suggests that the new women were placed in less electable positions in those lists that had chances of winning, an aspect to which we come back later. ${ }^{17}$

Overall, the data show a very significant effect of the equality law, increasing the share of women in the municipal lists and, to a smaller extent, the share of elected women. Moreover, the effects are very consistent throughout all the specifications, suggesting this natural experiment provides us with a robust empirical design. Hereafter we treat the increase in female politicians in the treated municipalities as exogenous and exploit this source of variation to identify the causal effect of female political candidacy on turnover and electoral results.

\subsection{Availability of Qualified or Willing Women}

It is possible that female political under-representation be explained by the lower supply of qualified and willing female candidates. After all, according to the Spanish statistical office (Instituto Nacional de Estadística) only $34.08 \%$ of party affiliates in the largest parties were women in 2007, and an estimate for 2003 is of about 33\% (Verges, 2006). Yet these statistics cannot account for the even lower percentage of women at the top of the local lists in 2003 (only 16\%), or top 2 (22\%), or for the smaller share of elected women in 2003 $(28 \%)$, suggesting that women affiliated with parties were placed in less electable positions. Furthermore, the number of relevant positions in the lists is very small and it should be straightforward to find enough female candidates if voter demand justified increasing the female share. Indeed, we provide here further evidence that is inconsistent with parties

\footnotetext{
${ }^{16}$ In Appendix Table 2 we vary the bandwidth around the treatment threshold of 5000 inhabitants in various ways, and the results are entirely consistent throughout, not only in terms of the sign of the coefficients, but also in the size of the effects.

${ }^{17}$ If the order of female candidates in the lists were random, we would obtain the same coefficient for the effect of the law on the share of female candidates and female elected candidates.
} 
having trouble to find qualified female candidates for their lists.

The first test to see if there was a lack of qualified female candidates implies analyzing the patterns of list survival after the law. This analysis is also important to assess to which extent previous results could be explained by list attrition correlated with the law. In Table 3 , column 1, we present the results of a linear model where we account for the probability of a 2003 list not repeating in 2007. The regression, which includes national party fixed effects and population size polynomials, does not find any relationship between list attrition and female quotas. The number of women in 2003 was not generally associated with attrition either, and the only variable that predicts attrition was the share of vote in 2003 (more-voted parties tended to repeat). The results in column 2 show further that it did not appear to be substantially harder to come up with minimally-qualified female candidates for those lists that were far from the 40 percent female target in the treated municipalities. Finally, in column 3, we see that the law was not associated with a lower propensity for new lists to arise either. Here we are using 2007 list data and the dependent variable is a dummy that takes value one if the list did not appear in the previous elections (a new list). If the absence of qualified or willing women had been a major issue we would have expected to find some effect on list formation, if only for the more marginal lists.

Another margin of adjustment if qualified women were scarce would have been to increase the retention rate of existing willing female candidates. Since we have the full name of candidates we can trace their participation across years and lists. Interestingly, in the untreated municipalities in 2007 the probability that a woman had already been in the list on the previous election - 32 percent - was much lower than the equivalent percentage for men: 43.55 percent. Women candidates experienced higher turnover between elections than men, a fact that is not explained by the position in the list they occupied (similar results are obtained when conditioning on list rank). Therefore, if qualified women candidates were truly scarce one would expect more efforts geared toward increasing their retention rate. In Table 4, we estimate linear probabilistic models with the following structure:

$$
X_{c i t}=\varphi_{1} D_{i E L} \times D_{07}+\varphi_{2} D_{07}+P_{d}\left(\varphi^{\prime}, P_{o p} i t\right)+\sum M_{i}+\varepsilon_{c i t}
$$

where $X_{c i t}$ is a dummy or indicator variable describing an attribute of candidate $c$ in town $i$ at time $t$. In column 1 the dummy variable takes value unity if the candidate is a women: $\varphi_{1}$ here is the impact of the quota on the share of women. ${ }^{18}$ In column 2 the dependent variable is now a dummy that takes value one if the candidate is a women appearing for the

\footnotetext{
${ }^{18}$ The estimates are now slightly-differently estimated. Concretely, in Table 2 each municipality is an observation whereas here we are giving more weight to municipalities with more candidates. Note that we are now genuinely interested in candidate-level estimates.
} 
first time in the list in 2007. The coefficient estimates are very similar to those in column 1: parties did not fill in the new "female" positions required by the quota by increasing the retention of women, but just brought in new women to the lists. In columns 3 and 4 we repeat these regressions, this time focusing in the top five positions. While the quota had to imply an absolute increase in the number of women overall, parties could have easily shifted existing incumbent lower-ranked candidates into the top positions. What we find, however, is that 81 percent of these top- 5 positions were actually filled with new women, and this share increases to 87 percent for the top-3 positions. When parties were forced to place females in top positions new women stepped in to take on the challenge.

All in all, existing and new parties in towns affected by female quotas did not make efforts to increase the retention rate of past women candidates and did not have any problems filling their lists with more and new female candidates. At the top, parties did not need to promote lower-ranked candidates. There was no list attrition or increased difficulties for new lists to arise. This evidence is not consistent with the existence of major supply constrains on qualified female candidates.

\subsection{Do Voters Dislike Female Politicians?}

\subsubsection{Voter Turnout and Protest Votes}

As we discussed earlier, an important test to gauge the existence of voter preferences or differences in quality between male and female candidates is to examine changes in turnout rates associated with an exogenous increase in the number of female politicians: did some voters stay at home more often rather than voting for female candidates?

In table 5 we analyze the relationship between female-politician frequency and voter participation. Voter turnout is quite high in these local elections (with an unweighted average of 73 percent of registered voters across the treatment and control municipalities attending to the polls).

It is very difficult a priori to know if the presence of women politicians is frowned upon by some voters. In fact, in Table 5 column 1 , simple OLS regressions at the municipality and year level (standard errors clustered by municipality) point in the opposite direction: municipalities with more women in the lists tend to have higher voter turnouts. A town with a ten percentage point higher share of female politicians can be expected to have a 1.45 percentage increase in voter turnout. Of course, this may only reflect the fact that in towns with a more participative culture (or social capital) women are also more likely to become politicians, an interesting fact by itself that we red-flag for future research. However, the Equality Law provides us for an exogenous source of variation to examine the causal impact 
of female politicians on citizen interest in local politics. To do so we deploy the empirical model:

$$
V T_{i t}=\phi_{1} \text { FemSha }_{i t}+\phi_{2} D_{07}+P_{d}\left(\Phi^{\prime}, P_{o p} p_{i t}\right)+\sum M_{i}+\varepsilon_{i t}
$$

Where VT stands for the voter turnout rate in town $i$ at time $t=03,07, F e m S h a_{i t}$ is the share of female candidates in the elections by municipality and year, and the rest of the notation is consistent with previous specifications. In order to take advantage of the large exogenous increase in women participation we instrument the share of women candidates with $D_{i E L} \times D_{07}$, which is effectively an indicator for the treated municipalities after the law was enacted. The results, in Table 5 column 2, suggest that the positive association between women political activism and voter participation was not causal. The coefficient is a relatively precisely estimated zero.

Column 3 uses a more elaborate instrumental variable strategy. The share of women candidates by municipality in 2003 was not affected by the change in law, as it could not be anticipated at that time that such law would be passed. Therefore, we can construct a measure of how binding the law was for each municipality as the difference between the share of female candidates in 2003 and the 40 percent required in 2007. We now therefore use $D_{i E L} \times D_{07} \times \max \left\{0,0.4-F e m S h a_{i 03}\right\}$ as alternative instrument, yielding the same nonsignificant results. The advantage of this alternative instrument is that now we are exploiting differences in how binding the law was across treated municipalities. In municipalities where women were already active above the 40 percent threshold the law did not represent a significant change to the electoral landscape. But it did in municipalities were women were more severely underrepresented. In fact, in column 4, we go further and limit the sample to treated municipalities only (between 5000 and 8000 inhabitants) therefore dispelling any potential concerns about the quality of the control group. All of the variance is coming now from the dosage intensity in the treatment effect (law-driven change in the female politician share) on the treated municipalities; the estimates are identical.

Finally, in column 5 we repeat a similar specification as in column 2, this time focusing on the effects of female politicians on the share of blank or null votes. These votes do not affect the results of the elections but voters could use them as a message of disapproval with the political process. To the extent that voters were unhappy with an increasing leading role of women in the electoral process, we may see an effect on this type of votes. However, the results show no significant effect of female participation on the share of protest votes.

While we do not know the gender of the electorate (this information is kept confidential) we remark that these zero results do not change across municipalities by the share of women in the population. It appears therefore, unlikely that an increase in the propensity of women 
to vote offsets a corresponding decrease in male voters. Note further that, in any case, votemaximizing parties should not care about the identity of the electorate, but focus on the total number of votes.

Overall, the patterns on voter turnover cannot offer a conclusive test to discriminate among the different theories of low female participation. However the data are generally not supportive of theories of voter demand for discrimination, as we did not see a decrease in voter turnout or an increase in protest votes when and where the number of women politicians increased by 25 percent due to the quotas.

\subsubsection{Female Politicians and Electoral Results}

The previous tests can be especially powerful against alternatives under the null hypothesis that voters had strong preferences against female candidates, and those preferences were quite homogeneous across lists. However, voters of different ideologies may have diverging preferences. In that case, parties with a more biased electorate could optimally choose to field fewer female candidates. As discussed earlier, an alternative, if observationally equivalent, theory has different parties being differently endowed with high-quality female candidates. Parties that systematically have more difficulty finding qualified women politicians should field less female candidates. Both theories suggest that exogenously forcing more female candidates into lists in which these are underrepresented should reduce their electoral success. Therefore we next examine if the lists in which the law was more binding lost electoral ground after the law. The intuition for this approach can be reinforced by looking back at Table 1. It is clear that treated electoral lists that concurred both to the 2003 and 2007 elections and had a relatively small number of women on their lists had to make very large adjustments vis-a-vis lists in the control group. Conversely, the growth in the share of women was much smaller or nonexistent in the lists that had fielded 5 or more women in 2003 with respect to the counterfactual. This suggests using the distance of the list to the 40 percent quota in the treated municipalities as a list-specific instrument for the exogenous growth in the lists' female share. Concretely, the model that we estimate takes the form:

$$
\triangle V \text { otSha } a_{k i}=\beta_{1} \triangle F e m_{k i}+\sum M_{i}+\sum P A_{k}+\varepsilon_{k i}
$$

$\triangle V$ ot $S h a_{k i}$ is the change in the vote share for party $k$ in municipality $i$ between 2003 and 2007 , and $\triangle F e m_{k i}$ the change in the number of women in the party's list. $P A_{k}$ stand for party fixed effects: one dummy for each party that fielded lists in more than 10 municipalities and an "other" dummy for the unaffiliated lists (only 11 percent of the total). The party fixed effects capture changes in voter sentiment toward the national or regional parties, 
which also tend to be dominant in local elections. Note that it is important here to include municipal fixed effects $\left(\sum M_{i}\right)$ because overall changes in voting share should add to zero across lists in the same municipality and the impact of a symmetric increase in the dependent variables across all lists should wash out. Such symmetric changes within municipalities will be captured by the municipal fixed effects. Therefore, the results should be interpreted as relationships between the variables' deviations from their municipal means, which is in line with what the model suggests is the appropriate comparison to test the various theories. In this specification, we instrument $\triangle F e m S h a_{k i}$ with the variable: $D_{i E L} \times \max \left\{0,5-F e m_{k i, 03}\right\}$ : the pre-treatment distance to the minimum quota target ( 5 women in the treated sample) interacted by an Equality Law treatment dummy. Intuitively, more women were "forced" into lists that used to have fewer female candidates in order to comply with the quota (indeed the first stage yields a coefficient of one and the instruments are very strong).

In Table 6, column 1, we first limit the estimation to the municipalities exposed to the law. All the variance here is coming from the shock to female candidates implied by the initial number of women in each list. The evidence is not supportive of the hypothesis that the vote share decreased in those lists where a higher number women than optimal was imposed by the law. In fact, surprisingly, we do find positive effects of bringing more women to these lists. These results are confirmed in column 2, where we include the observations from the control group (unaffected by the law).

Due to the unpredictability of the enactment of the law after the Madrid bombings and the subsequent unexpected results in the general elections of 2004, it is very unlikely that parties in treated municipalities had anticipated the effect of the law by strategically choosing the number of female candidates in 2003. Yet one of the concerns in these specifications is that the initial number of women could be signaling party attributes whose valuations were changing between 2003 and 200\%. While lists with less women in 2003 may have been different, note that because we are using first differences in the relevant variables we are effectively removing any list-specific effects that do not change in time. Furthermore, we did not find any evidence that the number of women in 2003 was predictive of changes in voting shares in the control group or in an alternative sample of all untreated municipalities with populations below 2000 inhabitants. However, the existence of a control group allows us to be able to control for the number of women in 2003 on the right-hand side, which we do in column 3. ${ }^{19}$ The results are now even larger albeit much more imprecisely estimated: the lagged female candidate control is, of course, highly co-linear with the instrument. Clearly,

\footnotetext{
${ }^{19}$ The results are robust to assuming non-linearities in the effect of previous female candidates. Including a set of fixed effects for each number of women in 2003 did not change the coefficients in column 3 , and the pre-treatment-women fixed effects cannot be deemed to be statistically different from zero.
} 
there is no evidence of a negative impact of women on voting shares. Moreover, we cannot reject a null direct effect of the lagged number of women candidates on voting share growth, which is the assumption that we carry forward.

A second concern with these results is that they may be driven by higher candidate turnover. Indeed, one of the effects of the quota was to increase the number of new candidates. Could it be that voters relatively dislike women but like new candidates and that the latter effect dominated after the law? In column 4 we also control for the share of candidates who were new to the list in 2007, but results do not change. We finally control for potential incumbent effects in column 5 by introducing a dummy for lists that were the most voted in the previous elections. While we do find evidence of wear-down for incumbent lists, that does not change the relevant results.

The results are quite precisely estimated. Quantitatively, consider the hypothetical case of a party that ran with 2 women candidates in 2003, whereas the remaining parties were fielding 5 each. Assuming that the other parties did not change the number of women, this hypothetical list would be required to field 3 more women by law, increasing its voting share by 2.7 percentage points. These results are clearly inconsistent with the hypothetical existence of voter discrimination or with lower political ability of female candidates. Instead, the results suggest the presence of party discrimination.

To examine further the nature of the positive impact of women, we separate the sample of lists by the level of competition in their municipalities. Electoral results at the municipal level are quite persistent. The correlation between the number of seats for repeat lists across the two elections was 0.86 . At the top, 75 percent of the winning lists in 2003 repeated as winners in 2007. Losing lists in 2003, conversely, only had an 11 percent chance of winning. The percentage of repeat winning lists increases to close to 90 percent in those municipalities that we deem non-competitive. In our definition, non-competitive municipalities are those where the largest party obtained 7 or more seats (out of a total of 13) in 2003, an absolute majority.

In column 6 (Table 6) we present separate results for non-competitive municipalities and contrast them to those in more competitive environments (column 7). The results suggest that the positive impact of women on electoral returns was concentrated in non-competitive municipalities. Parties there seemed to have deviated more from the optimal gender mix.

In Table 7 we examine this issue further. Concretely we now ask if the initial share of women politicians had been lower in noncompetitive municipalities relative to others. These are purely descriptive OLS regressions with the share of women candidates in 2003 on the left-hand-side and a dummy for non-competitive municipalities in that year on the righthand-side, together with population polynomials. The results in column 1 do not allow us 
to infer any differences. However, when we focus on the more relevant top 5 positions, there is some indication that parties in non-competitive towns were fielding less women (column 2). We then add a dummy for the winning list, and interact it with the non-competitive election indicator. The descriptive evidence in column 3 is quite conclusive: entrenched winning parties in non-competitive elections were fielding females in electable positions at a rate 3.3 percentage points below the average (representing a $10 \%$ decrease in the number of such electable females). In other words, men tended to be more prevalent in relatively "safe" positions for council seats. This observation, together with the fact that it was precisely in those same positions that women increased votes, go against the view that males generally perform better as politicians and that more males were thus required by party machines to win these elections. This evidence is very consistent with Sanbonmatsu's (2006) finding that "women are less likely to run for and hold state legislative offices where parties are stronger;" and with Bagues and Esteve-Volart (2010) who find that males are typically selected for the "safest" seats in the Senate.

The results are therefore more consistent with the view that lower female political activism at the local level is not due to voter preferences or low ability, but to internal dynamics within the parties. In incumbent parties that operated in less competitive environments these gender power dynamics were more prevalent, perhaps because of the existence of entrenched male candidates and the lesser need to appeal to broader constituencies. On the contrary, in closer elections competition seemed to have mitigated party insiders' ability to discriminate, thereby fielding the most electable candidates for the list.

\section{Alternatives to Voters' Tastes}

\subsection{Did Women Shy Away from Competitive Positions?}

All of the evidence so far points to the existence of internal party dynamics to explain lower female political power, as opposed to voter preferences or a lack of women who are qualified and willing. Political parties seem to behave as if they have preferences for fielding male candidates $\left(d_{0}, d_{1}>0\right.$, in the model). One explanation for these "preferences" could come from the behavior of women in competitive situations.

A number of papers demonstrate that women feel less comfortable and are less productive in competitive environments (Niederle and Vesterlun, 2007). This may lead females in

political parties to avoid competition by avoiding being in the list or by avoiding confronting other candidates for better positions within the lists. Observably equivalent hypotheses have female candidates wanting to avoid the stress or responsibility associated with more pow- 
erful or visible positions, or weighting the negative impact of child-rearing over the ability to successfully perform as a leader. Did women systematically shy away from influential positions?

A way to test a strong null hypothesis on those lines is to consider what the outcome should be if women focused solely on avoiding confrontation with males for high-responsibility or more-visible positions. In this case, the more intrinsically-motivated male candidates would be completely successful in capturing the highest positions in the list. Because the Equality Law had women occupy two positions in the more influential top five spots of each list, we would expect women to systematically occupy positions 4 and 5 if their objective was to minimize political responsibility. In Table 8, we examine the impact of the law on the share of women at different levels in the lists. These are regressions at the list level (conditioning on parties that appear in both elections), using both the pre-treatment and post-treatment observations of both the treated and control municipalities and list fixed effects in order to control for party and municipal unobservables. The results confirm that the average treated list experienced an increase in the share of women of 8 percentage points in the top 5 positions (column 1). Interestingly, however, the impact of the law was of only 4.6 percentage points in the top 3 positions (column 2) and of 0.36 percentage points in the top position (mayoral candidate). This suggests that, indeed, women candidates tended to place in the lower positions: they were twice more likely to occupy positions 4 and 5 than positions 1, 2, and 3. On the other hand, it seems that a considerable number of the new women in the lists used the law to gain bargaining power, obtaining access to better positions than those regulated by law.

In columns 4 through 6 we repeat the exercise, this time focusing on the lists that had won the 2003 election. In these lists, where the top 3 positions consisted of "safe" seats for the incumbent party, women had a harder time cracking through the "glass ceiling" of position 4. In fact, the new women never dislodged existing mayoral candidates in these incumbent lists.

On the other hand, the new women forced into at least the top 4 and 5 positions by the quota were quite likely to make it into the top 3 positions and as number one in the nonincumbent lists (albeit still below what one would expect from equal-chance randomization). Clearly, many of these women took the opportunity provided by the law and leveraged their increased bargaining power to fight for the top positions. This evidence seems inconsistent with a strong null hypothesis of generalized female lack of intrinsic motivation for power or observationally equivalent hypotheses. While previous literature incontestably establishes that women are less keen to compete on average and child rearing might be an issue for many women, this need not affect much equilibrium outcomes for the females at the very 
right tail of the competitiveness distribution if $i)$ the number of power positions is very small so that there are many more qualified/ambitious women than positions; ii) consumers prefer a more balanced gender mix; iii) markets are competitive so that entrenched male insiders cannot discriminate against women.

Indeed, both the facts that these new women at the top in competitive lists needed the law to leverage on their ambitions, and that their counterparts in incumbent parties did not make it to the top appear more consistent with the existence of entrenched male insider interests, and with perpetuating gender-power dynamics within the parties' political machines.

\subsection{Endogenous Supply of Qualified Women: Using High-Status Names as Markers}

An additional explanation for the evidence so far has the supply of available qualified women endogenously increasing after the quota in the treated municipalities. By increasing the likelihood of being selected, quotas could make it more appealing for highly-qualified women to participate in the political process. Alternatively, the quotas could have helped break a bad Nash equilibrium: prior to the quota, qualified women did not show up because of a perceived lack of opportunities, and parties were fielding less women for lack of qualified candidates. In that case, voters may have reacted positively to the higher quality of the new female candidates, rather than showing their preference for more gender-balanced lists. Note that if parties were informed and forward-looking, these stories imply, in the end, discriminatory behavior: political machines were offering lower positions to women, therefore screening out highly-qualified ambitious females at the cost of future lower voting shares.

However, the law made it more likely for women to be elected in all parties. Thus, a general tendency for the law to attract more highly-qualified women might have resulted in a wash, and need not have been associated with party-specific electoral gains. Furthermore, a hypothetical endogenous increase in the supply of high-quality women across the board cannot explain why it is precisely the non-competitive municipalities that drive the electoral results.

In order for an endogenous change in the distribution of available women politicians to explain the results, this candidate quality ought to have increased substantially more in noncompetitive incumbent parties than in others. But even in that case, such a theory could not explain why non-competitive incumbent parties used to field less women candidates prior to the law in the first place. Moreover, this alternative explanation also seems inconsistent with the fact that incumbent parties were more likely to place the new women precisely in 
positions 4 and 5, the lowest positions required by the law. If the new women in incumbent parties were now relatively more qualified than the new women in other parties, we would have expected the opposite to happen absent discriminatory preferences.

Yet, perhaps more elaborate stories could be produced to hypothesize the existence of an endogenous-quality effect. We can address this concern more directly by searching for evidence of a change in the quality of the female candidate pool after the quota in the treated municipalities. Unfortunately, we do not have any information about the candidates themselves besides their name and gender. However, we can use the information about socioeconomic status conveyed by names to gauge whether higher-status candidates were attracted by the quotas.

A recent literature has pointed to the informational content of characteristically ethnic names (Fryer and Levitt, 2004) or the surname choice of married women in the US (Goldin ans Shim, 2004). Name assignation entails a conscious choice by parents, and is therefore influenced by their cultural milieu,revealing clues about their socioeconomic status (SES).

To operationalize this idea, we start by calculating the power status of all female first names that appeared in the 2003 municipal lists. We have 70,556 female candidates and 1,388 distinctive first names. Female first names in this sample follow a Pareto-like distribution with a few names accounting for a large fraction of the population. A surprising 38 percent of the candidates have Maria or one of its composites (e.g. Maria Rosa) as their first name. The top 20 names account for 60 percent of female candidates. In order to estimate accurate status measures we focus on 212 names with more than 25 observations (encompassing 93 percent of the female sample). For such each name-and the alternative category "other name"-we calculate the average share of women that were elected in the 2003 elections. $^{20}$ We create a power index for each name by dividing the share of elected women bearing that name by the average share of elected women in 1993 (approximately one in five women resulted elected). In Table 9, panel A, columns 1 and 2 we display the names with the highest and lowest relative eligibility. Low-status names in particular seem to follow two patterns: they conform to our priors about naming conventions in low SES populations, or correspond to names that became popular only recently (e.g. Laia or Mireia in the mid 80s and 90s) and therefore single out very inexperienced candidates. Interestingly, the pervasive "Maria" has no informational content, with an electability ratio close to one. Smaller names in the "other" category are, on average, also non-informative. Note that there is more information on the left tail of the status distribution: many of our top powerful names are already close to the average in terms of electability, but low-status names are genuinely less powerful. We

\footnotetext{
${ }^{20}$ Note that this measure combines the likelihood of joining a winning list with the likelihood of being closer to the top of the list.
} 
will therefore feel more comfortable inferring low power status in 2007 to candidates with names for which we calculate a relatively low electability in 2003.

We can also obtain information about the SES of candidates from their surnames. While first names arise from a conscious choice by parents, surnames are passed on for generations. Therefore, their informational content is influenced by inherited attributes, such as genes, income, education,... (Guell, et al., 2007). Fortunately for our study, the two papers we are aware of studying the informational content of surnames both focus on the case of Spain. Collado, Ortín, and Romeu (2008) use yellow pages and other sources and find that individuals with low-frequency surnames in Spain tend to be more likely to be doctors, lawyers, and university professors. Individuals with rare surnames had also been more likely to be literate in the 1890 historical Census. With respect to political power, these authors also find low-frequency surnames to be over-represented amongst political candidates in the 2004 national congress and Senate elections, but this effect is solely driven by the conservative and nationalist parties. ${ }^{21}$ Similarly Guell et al. (2007) use confidential Census data and find that "the more frequent a surname is, the less education should you expect her holder to have achieved."

People in Spain use two surnames: first the father's first surname, and then the mother's first surname. A traditional way to achieve high-status surname differentiation in Spain has been to hyphenate two surnames (e.g. Garcia-Parra) and then use another one from the parents as a second surname (see Salazar-Acha, 1991). Similar strategies have historically implied using prepositions to compound a surname with another one or a geographic location (e.g. Sanchez de la Ensenada). Such "double-barreled" surnames tend to be carried by individuals of measurably high socioeconomic status (Collado et al., 2008).

The insights above allow us to infer higher likelihood of a better education and SES in the following ways: i) we create a dummy that takes value one if the candidate is female and her first name power-status (relative electability in 2003) is below 0.9, corresponding to the lowest quartile in the name distribution ${ }^{22}$; ii) we create a dummy that equals one if the candidate is female and has a rare first surname; rare surnames are such that the number of female candidates bearing that surname was less than or equal to 5 (out of 70,556) in 2003 (this corresponds to the lowest quartile of the female distribution by surname frequency); iii) we create a dummy equal to 1 for women with a first surname in the list of the top 17 surnames encompassing 25 percent of the total candidate population in $2003 .^{23}$ Those

\footnotetext{
${ }^{21}$ Note that most recent immigrants that arrived after 2002 were largely ineligible to vote or join a list in the 2003, 2004, and 2007 elections. Prior to that period, immigration levels in the country were very low.

${ }^{22}$ Results are not sensitive to changing this threshold or on focusing on the right-tail of the status distribution.

${ }^{23}$ For both measures ii) and iii) we find no additional value - in terms of predicting electability —in adding
} 
extremely common surnames (e.g. Gonzalez, Garcia) can be seen in Table 9, panel A, column 3 ; iv) we create a dummy that takes value one if the candidate is a female and her surname is longer than the conventional 3 words. To calculate the number of words we separate hyphenated surnames into two words and count as words the usual connecting prepositions (e.g. "de", "la").

Remarkably, we find the surname strategies to be successful in replicating the patterns suggested by the previous literature. Focusing on the likelihood of each female candidate resulting elected in 2003 (about 20 percent on average), we find that women with lowfrequency surnames were 1.5 percentage points more likely to be elected than the median, and that women with the very common surnames were less electable in the same proportion. Individuals with names longer than the conventional 3 words were 2 percentage points more likely to be elected, a remarkable 10 percent increase in such probability. These are, in our view, large effects. Reassuringly, surname rarity, not bearing one of the common surnames, and name length all increase significantly the likelihood of bearing a high-status first name, which further validates the informational content of these alternative measures. ${ }^{24}$

In Table 9, panel B, we look at whether the Equality-Law quota increased the educational and social status of the women candidates in treated municipalities as captured by the name measures. To do so, we present models of the 2003 and 2007 elections where each candidate represents an observation, and include municipal fixed effects to control for local unobservables. On the left-hand side, the female status measures take value zero for all males, and one or zero for females depending on whether they bear a high or low-status name. The main controls on the right-hand-side are: a baseline dummy for female candidates, a dummy for female candidates in municipalities affected by the law, a dummy for female candidates in 2007, and a dummy for female candidates in municipalities affected by the law in 2007. The coefficient of interest is the latter one. Note that the fully-interacted model allows us to interpret the coefficient of the female dummy as the baseline probability of women to be in a low or high-status group, and to benchmark the other coefficients accordingly. In order to give the "endogenous quality" hypothesis a better chance we present separate regressions for the top 5 positions and the rest. Presumably, high-quality women specifically attracted by the power quotas would want to go at the top of the lists. ${ }^{25}$

The results in Panel $\mathrm{B}$ of Table 9 do not display any evidence of an increase in the socioeconomic status of females in the quota municipalities after the law. ${ }^{26}$ Note that we the informational content of the second surname.

${ }^{24}$ The interested reader can consult appendix table 3 for these results.

${ }^{25}$ When we pool both samples, the results are similar both quantitatively and in terms of statistical significance.

${ }^{26}$ We also repeated the same analysis for the non-competitive municipalities, where the effect of the quotas 
have a large amount of observations and are, therefore, likely to pick up relatively small but systematic effects (in fact, the regressions do capture small temporal trends in some of the variables). If anything, the results tend to indicate that lower-status females were more likely to be included in the top 5 positions after the quotas (lower status names, less rare and more common surnames, and shorter names), but the individual coefficients are not statistically significant. We conclude that it is unlikely that the quotas resulted in marked increases in the quality of the female candidates in the field.

\section{Conclusion}

Recent research has emphasized the existence of differences in tastes and psyches between genders (Crosson and Gneezy, 2008). Lawless and Fox (2005) conducted a survey of potential women candidates in the US and report that women tend to see themselves as less apt political leaders on average. We argue that, while these issues are certainly important to account for the outcomes experienced by the average female, they do not necessarily explain why women are underrepresented in positions of power. Insofar there is demand for it in electoral markets, and party machines try to maximize votes in a competitive environment electoral lists should include a large fraction of women candidates, easily drawn from the very right tail of the female ability and ambition joint distribution. It is not possible to understand female under-representation in the relatively-few top positions independently from the market demand for talented female politicians and the behavior of party machines on the supply-side (Becker, 1957).

To frame this debate, we developed a model that nests most of the explanations of why women are underrepresented in powerful positions. Some factors that account for this problem may be mediated by markets. On the demand side, customers in the political process (voters) may prefer male candidates. On the supply side, there may be less willing qualified female candidates. Alternatively, the factors that determine the low availability of female candidates may stem from internal processes within the political parties.

We then took the predictions of the different hypotheses to the data. We used Spain's Equality Law as a natural experiment providing an exogenous increase in female political participation. The timing of the passage of the Inequality Law in 2007, establishing a 40 percent quota of women in all electoral lists, was exogenous and quite unpredictable. The Equality Law was passed in March 2007, just two months before the municipal elections.

An important feature of the Equality Law, was that it only applied in 2007 to munici-

is most pronounced. We do not find any evidence of an increase in the SES of female candidates in those municipalities either. 
palities with populations above 5000 inhabitants. We therefore implemented a discontinuity design that compared treated and control municipalities around that threshold before and after the law's passage.

Empirically, we found that the law increased the female candidate share by eight percentage points, representing an increase of 25 percent in the number of women candidates. Such large shock to the number of local female politicians did not have any adverse impact on voter turnout or protest ballots in the treated municipalities. We also found that parties did not have major problems finding suitable female candidates to fill in the quota. The female quota was not associated with increased list attrition or difficulties for new lists to arise. Parties did not need to retain past women candidates more often or to promote female "filler" candidates to top positions. This evidence is not consistent with the existence of major supply constraints of female candidates.

In addition, parties that were further from the 40 percent female threshold and were therefore forced to field in more female candidates experienced increases in their vote shares. The evidence is not consistent either with the existence of generalized strong preferences for male candidates amongst voters.

We further found that the positive effect of women on votes was concentrated in municipalities with non-competitive elections, where one party had enjoyed an absolute majority in the 2003 elections. In these municipalities, the incumbent lists had fielded a number of women that was significantly below the average in competitive elections. More men had been fielded in elections were the incumbent party had a large number of safe seats, but these parties subsequently fared better with more women in the next elections. All of these facts are at odds with the claim that more men are required to win elections.

Were parties and female potential candidates locked in a bad Nash equilibrium, with good woman candidates not showing up for lack of prospects and parties offering low positions to females due to lack of qualifications? We showed that further results are not consistent with this hypothesis. The quotas - forcing parties to offer some of the top positions to women- were unlikely to have attracted women of higher educational or socioeconomic status. Names and surnames convey SES and educational status in Spain; however there was no differential growth in the status of names or surnames of the female candidates in the treated municipalities.

The explanation for lower female representation seems to revolve around the internal dynamics of candidate choices within the parties: parties behave as if they displayed discriminatory tastes. Are women themselves opting for less powerful positions? While women may shy from competition on average, a large number of women in competitive lists leveraged the Equality Law to attain higher positions than the minimum ones guaranteed by the 
quota. However, female candidates had more difficulty attaining top positions in relatively "safe" top spots in incumbent lists. The evidence seems overall more consistent with the existence of entrenched male-dominated political machines, especially in less competitive environments.

The results demonstrate that forcing parties to accept more women through quotas on the candidate lists can increase female participation without necessarily decreasing the electability of the candidates. But at the same time, competition may also limit the scope for discrimination from party machines. Hence, alternative policy responses could imply more reliance on party primaries at all levels, open lists, voting for candidates rather than lists, and more competitive electoral environments with less "safe" seats at the disposition of party machines. We hypothesize that such measures could also induce more females to participate in the political process, without having to impose strict quotas, a testable hypothesis for future research on this topic. In fact women representation is much larger in proportional electoral systems (Norris, 2006, Norris and Krook, 2011) where each vote counts, as opposed to majoritarian systems where many seats are de-facto owned and non-competitively allocated by the machines of the locally dominant party, especially after redistricting. Effecting the behavior of political machines vis-a-vis gender issues and understanding how competition changes these dynamics could thus be the keys to improve female chances at equal participation.

\section{References}

[1] Arrow, Kenneth J. 1973. "The theory of discrimination," O. Ashenfelter and A. Rees (eds.), Discrimination in Labor Markets, Princeton, NJ: Princeton University Press.

[2] Ayres, Ian, and Peter Siegelman. 1995. "Race and gender discrimination in bargaining for a new car," The American Economic Review, 85(3): 304-321.

[3] Bagues, Manuel F., and Berta Esteve-Volart. 2010. "Can gender parity break the glass ceiling? Evidence from a repeated randomized experiment," The Review of Economic Studies, 77(4): 1301-1328.

[4] Bagues, Manuel F., and Berta Esteve-Volart. 2009. "Are women pawns in the political game? Evidence from elections to the Spanish Senate," mimeo.

[5] Beaman, Lori, Raghabendra Chattopadhyay, Esther Duflo, Rohini Pande, and Petia Topalova. 2009. "Powerful women: Does exposure reduce bias?" The Quarterly Journal of Economics, 124(4): 1497-1540. 
[6] Becker, Gary. 1957. The economics of discrimination. Chicago: University of Chicago Press.

[7] Bertrand, Marianne, Claudia Goldin, and Lawrence F. Katz. 2010. "Dynamics of the gender gap for young professionals in the financial and corporate sectors," American Economic Journal: Applied Economics, 2: 228-255.

[8] Campa, Pamela (2010). "Legislative Gender Quotas and Public Childcare Provision: Quasi-Experimental Evidence." Mimeo: Stockholm University.

[9] Cavalcanti, Tiago V. and Jose Tavares (2011), "Women Prefer Larger Governments: Growth, Structural Transformation, and Government size" . Economic Inquiry, 49: $155-171$.

[10] Chattopadhyay, Raghabendra, and Esther Duflo. 2004. "Women as policy makers: Evidence from a randomized policy experiment in India," Econometrica, 72(5): 1409-1443.

[11] Clots-Figueras, Irma. 2009. 'Are Female Leaders Good for education? Evidence from India,' Mimeo, Universidad Carlos III.

[12] Collado, M. Dolores, Ortín, Ignacio Ortuño and Romeu, Andres, (2008), "Surnames and social status in Spain." Investigaciones Economicas, 32-3, pp. 259-287.

[13] Crosson, Rachel, and Uri Gneezy, 2008. "Gender Differences in Preferences." Journal of Economic Literature, 47:2, 1-27

[14] De Paola, Maria, Vincenzo Scoppa, and Rosetta Lombardo. 2010. "Can gender quotas break down negative stereotypes? Evidence from changes in electoral rules," Journal of Public Economics, 94: 344-353.

[15] Dolan, Kathleen A. 2004. "Voting for Women. How the Public Evaluates Women Candidates." Westview Press: Boulder, Colorado.

[16] Dolan, Kathleen A. 2005. "Women Candidates in American Politics: What We Know, What We Want to Know." Presented at the 2006 meeting of the Midwest Political Science Association, April 20-23, 2005.

[17] Dufflo, Esther and Petia Topalova (2004)/ Unappreciated Service: Performance, perceptions, and Women Leaders in India." MIT Working Paper.

[18] Einav, L. and L. Yariv (2006) "What's in a Surname? The Effects of Surname Initials on Academic Success", Journal of Economic Perspectives, 20, 175-188. 
[19] Ferreira, Fernando and Joseph Gyourko (2010). "Does Gender Matter for Political Leadership? The Case of U.S. Mayors " Mimeo: university of Pennsylvania.

[20] Fryer, R.G., Jr. and S. D. Levitt (2004) "The Causes and Consequences of Distinctively Black Names", Quarterly Journal of Economics, 119(3), 767-805.

[21] Funk, Patricia and Christina Gathman, 2010 "“Gender Gaps in Policy Making: Evidence from Direct Democracy in Switzerland", Mimeo: Universitat Pompeu Fabra.

[22] Gallarduci, Stefano and Daniele Passerman, 2010. "Gender Interactions within Hierarchies: Evidence from the Political Arena." Working Paper: Boston University.

[23] Gneezy, Uri, Muriel Niederle, and Aldo Rustichini. 2003. "Performance in competitive environments: gender differences," The Quarterly Journal of Economics, 118(3): 10491074.

[24] Gneezy, Uri, and Aldo Rustichini. 2004. "Gender and competition at a young age," The American Economic Review: Papers and Proceedings, 94(2): 377-381.

[25] Goldin, Claudia, and Lawrence F. Katz. 2008. "Transitions: Career and family lifecycles of the educational elite," The American Economic Review: Papers and Proceedings, 98(2): 363-369.

[26] Goldin, Claudia, and Cecilia Rouse. 2000. "Orchestrating impartiality: The impact of "blind" auditions on female musicians," The American Economic Review, 90(4): 715741.

[27] Goldin, C. and M. Shim (2004), "Making a name: Women's Surnames at Marriage and Beyond", Journal of Economic Perspectives, 18(2), 143:160.

[28] Güell, Maia and José V. Rodriguez Mora \& Chris Telmer, 2007. "Intergenerational Mobility and the Informative Content of Surnames," Economics Working Papers 1042, Department of Economics and Business, Universitat Pompeu Fabra.

[29] Montalvo, Jose G. (2009). "Voting after bombings: a natural experiment on the effect of terrorist attacks on democratic elections" forthcoming in the Review of Economics and Statistics

[30] Kahn, Lawrence M. 2000. "The sports business as a labor market laboratory," The Journal of Economic Perspectives, 14(3): 75-94. 
[31] Knowles, John, Nicola Persico, and Petra Todd. 2001. "Racial bias in motor vehicle searches: Theory and evidence," The Journal of Political Economy, 109(1): 203-229.

[32] Niederle, Muriel, and Lise Vesterlund. 2007. "Do Women Shy Away from Competition? Do Men Compete Too Much?" Quarterly Journal of Economics, 122(3): 1067-1101.

[33] Norris, Pippa (2006). "The Impact of Electoral Reform on Women's Representation." Acta Politica, Volume 41, Number 2.

[34] Norris, Pippa and Mona Lena Krook (2011). "Gender Equality in Elected Office: A Six Step Action Plan." OSCE Draft Report.

[35] Lawless, Jennifer and Richard Fox. 2005. It Takes A Candidate: Why Women Don't Run for Political Office. New York: Cambridge University Press

[36] Price, Joseph, and Justin Wolfers (2010) "Racial discrimination among NBA referees," The Quarterly Journal of Economics, 125(4): 1859-1887.

[37] Rehavi, M. Marit (2007) "Sex and Politics: Do Female Legislators Affect State Spending?" Mimeo, University of California, Berkeley

[38] Reuben, Ernesto, Pedro Rey-Biel, Paola Sapienza, and Luigi Zingales (2010) "The Emergence of Male Leadership in Competitive Environments." IZA Discusion Paper No. 5300.

[39] Sanbonmatsu, Kira (2002) "Political Parties and the Recruitment of Women to State Legislatures." Journal of Politics 64: 791-809.

[40] Sanbonmatsu, Kira (2006) "Where Women Run: Gender and Party in the American States." The University of Michigan Press: Ann Arbor.

[41] Saiz, Albert and Susan Wachter (2011) "Immigration and the Neighborhood." American Economic Journals: Policy (May, 2011).

[42] Salazar-Acha, J. (1991) Génesis y evolución histórica del apellido en España, Real Academia Matritense de Heráldica y Genealogía, Madrid.

[43] Szymanski, Stefan. (2000). "A market test for discrimination in the English professional soccer leagues," The Journal of Political Economy, 108(3): 590-603.

[44] Swers, Michele L. (1998). "Are Women More Likely to Vote for Womenís Issue Bills Than Their Male Colleagues?" Legislative Studies Quarterly, 23, 435-448. 
[45] Verge, Tania (2006) "Mujer y Partidos politicos en Espana: las estrategias de los partidos y su impacto institucional, 1978-2004," Revista Espanola de Investigaciones Sociologicas, 115: $165-196$.

[46] Welch, Susan (1985) "Are Women More Liberal than Men in the U.S. Congress?" Legislative Studies Quarterly, 10, 125-134 


\section{Appendix A: Proofs}

Throughout this section, we denote the variables that are chosen under the quota with the superscript $q$. We use $\Delta$ to denote the change in a variable after the introduction of the quota.

Proof of proposition 1. Because $f_{p m}=f_{p w}$, we can write $f \equiv f_{w}=f_{m}$ and $a_{p} \equiv a_{p w}=a_{p m}$. Let $F$ be the corresponding distribution function.

Each party chooses the best candidates for each gender. As a result, there is a one-to-one relationship between $\underline{a}_{p w}$ and $W_{p}$. Indeed, we can write

$$
W_{p}=\int_{\underline{a}_{p w}}^{\infty} f_{p w}(a) d a=\int_{\underline{a}_{p w}}^{\infty} f\left(a-a_{p}\right) d a=\int_{\underline{a}_{p w}-a_{p}}^{\infty} f(a) d a=1-F\left(\underline{a}_{p w}-a_{p}\right) .
$$

Because lists are of a fixed size, there is also a one to one relationship between $\underline{a}_{p w}$ and $\underline{a}_{p m}$, defined by the equation: $1-F\left(\underline{a}_{p w}-a_{p}\right)-F\left(\underline{a}_{p m}-a_{p}\right)=0$. As a result, if $W_{0}<W_{1}$, we must have $\underline{a}_{0 w}-a_{0}>\underline{a}_{1 w}-a_{1}$ and $\underline{a}_{0 m}-a_{0}<\underline{a}_{1 m}-a_{1}$ (when turnout is $100 \%$, it also follows that $d_{0}>d_{1}$ ). Moreover, under the quota, $\underline{a}_{p w}^{q}$ is chosen to satisfy $W_{p}^{q}=\underline{W}$ because the quota is binding for both parties. As both parties have the same share of women after the quota is imposed, we have that $\underline{a}_{0 w}^{q}-a_{0}=\underline{a}_{1 w}^{q}-a_{1}$ and $\underline{a}_{0 m}^{q}-a_{0}=\underline{a}_{1 m}^{q}-a_{1}$. Finally, notice that, because $W_{1} \leq \frac{1}{2}<1-W_{0}$, we have that $\underline{a}_{1 w}-a_{1}>\underline{a}_{0 m}-a_{0}$.

We show next that for all voters $x \in[0,1], u(x, 0)$ increases more than $u(x, 1)$ after the introduction of the female quota, i.e. $\Delta u(x, 0) \geq \Delta u(x, 1)$. To see this, notice that $\Delta u(x, p)=\Delta A_{p}-d_{v} \Delta W_{p}=\Delta A_{p}$, where

$$
\Delta A_{p}=\int_{\underline{\underline{a}}_{p w}^{q}}^{\underline{a}_{p w}} a f_{p w}(a) d a-\int_{\underline{a}_{p m}}^{\underline{a}_{p m}^{q}} a f_{p m}(a) d a .
$$

Notice that because $\underline{a}_{p w} \geq \underline{a}_{p w}^{q} \geq \underline{a}_{p m}^{q} \geq \underline{a}_{p m}, \Delta A_{p} \geq 0$ and therefore so is $\Delta u(x, p)$. Furthermore, we can write

$$
\begin{aligned}
\Delta A_{0} & =\int_{\underline{a}_{0 w}^{q}}^{\underline{a}_{0 w}} \text { af }\left(a-a_{0}\right) d a-\int_{\underline{a}_{0 m}}^{\underline{a}_{0 m}^{q}} a f\left(a-a_{0}\right) d a=\int_{\underline{a}_{0 w}^{q}-a_{0}}^{\underline{a}_{0 w}-a_{0}} a f(a) d a-\int_{\underline{a}_{0 m}-a_{0}}^{\underline{a}_{0 m}^{q}-a_{0}} a f(a) d a \\
& =\Delta A_{1}+\int_{\underline{a}_{1 w}-a_{1}}^{\underline{a}_{0 w}-a_{0}} \operatorname{af}(a) d a-\int_{\underline{a}_{0 m}-a_{0}}^{\underline{a}_{1 m}-a_{1}} a f(a) d a \\
& >\Delta A_{1}+\left(\underline{a}_{0 w}-a_{0}\right)\left[F\left(\underline{a}_{0 w}-a_{0}\right)-F\left(\underline{a}_{1 w}-a_{1}\right)\right]-\left(\underline{a}_{0 m}-a_{0}\right)\left[F\left(\underline{a}_{1 m}-a_{1}\right)-F\left(\underline{a}_{0 m}-a_{0}\right)\right] \\
& \geq \Delta A_{1},
\end{aligned}
$$

where the last inequality follows from the fact that $F\left(\underline{a}_{0 w}-a_{0}\right)-F\left(\underline{a}_{1 w}-a_{1}\right)=F\left(\underline{a}_{1 m}-a_{1}\right)-$ 
$F\left(\underline{a}_{0 m}-a_{0}\right) \geq 0$.

Since the utility from voting either party increases, turnout cannot decrease. Indeed, if turnout is less than $100 \%$ without the quota, it must increase after the quota is introduced.

We also need to see that $\Delta V_{0}>\Delta V_{1}$. If there is full participation without the quota, then $V_{0}=1-V_{1}$. The marginal voter, located at $x=V_{0}$ is indifferent between the two parties when no quota is present. However, because $\Delta u(x, 0)>\Delta u(x, 1) \geq 0$, this voter must strictly prefer to vote for party 0 when the quota is introduced. As a result, the quota moves the marginal voter closer to party 1 , so that $\Delta V_{0}>0>\Delta V_{1}$.

When there is a partial turnout in the absence of any quota we have $V_{0}+V_{1}<1$. Suppose that for each voter we increase the utility $u(x, p)$ of voting each party $p$ by $\delta$. Then, as long as $\bar{x}_{0}+\bar{x}_{1}+4 \frac{\delta}{t} \leq 1$, the number of votes of each party increases by exactly $2 \delta / t$ because transportation costs are linear and voters are uniformly distributed on the line. ${ }^{27}$ If quotas do not lead to full participation, then $\Delta V_{p}=2 \Delta A_{p} / t$. It follows immediately that $\Delta V_{0}>\Delta V_{1}$. Instead, if quotas result in full participation, we can increase the utility from voting each party in two steps. First, increase $u(x, p)$ by $\delta_{p}^{1}=\min \left\{\Delta A_{1}, \frac{t}{4}\left(1-V_{0}-V_{1}\right)\right\}$. In the second step we increase the utility of voting for party $p$ by $\delta_{p}^{2}=\Delta A_{p}-\min \left\{\Delta A_{1}, \frac{t}{4}\left(1-V_{0}-V_{1}\right)\right\}$. This way, we have that $\delta_{p}^{1}+\delta_{p}^{2}=\Delta A_{p}$, which is the full increase caused by the female quota. The increase in the first step is the same for both parties. Moreover, because $V_{0}+V_{1}+4 \frac{\delta_{p}^{1}}{t} \leq 1$, $V_{0}$ and $V_{1}$ increase both by the same amount. The increase in utility in the second step is larger for party 0 than for party 1 . Moreover, either there is full participation after the first step (if $\Delta A_{1} \geq \frac{t}{4}\left(1-V_{0}-V_{1}\right)$ ) or the utility of voting for party 1 does not increase in the second step (if $\Delta A_{1}<\frac{t}{4}\left(1-V_{0}-V_{1}\right)$ ). In either case, $V_{0}$ increases by more than $V_{1}$ in this second step. Therefore, adding the effects of the two steps, we get that $\Delta V_{0}>\Delta V_{1}$.

Proof of proposition 2. Notice that $1-F\left(\underline{a}_{p w}-a_{p}\right)-F\left(\underline{a}_{p m}-a_{p}\right)=1-F\left(\underline{a}_{p w}-a_{p}\right)-$ $F\left(\underline{a}_{p w}-d_{v}\left(\bar{x}_{p}\right)-a_{p}\right)=0$, since parties set $\underline{a}_{p w}-\underline{a}_{p m}=d_{v}\left(\bar{x}_{p}\right)$. Therefore, it is easy to see that $\underline{a}_{p w}-a_{p}$ is increasing in $d_{v}\left(\bar{x}_{p}\right)$. As a result, the number of women $W_{p}$ is a decreasing function of $d_{v}\left(\bar{x}_{p}\right)$.

If turnout is $100 \%$, the marginal voter is the same for both parties. As a result, both parties set the same difference for the standards of men and women, as $\underline{a}_{p w}-\underline{a}_{p m}=d_{v}\left(\bar{x}_{p}\right)=$ $d_{v}(\bar{x})$. Because the distribution of ability for men and women is the same, this means that both parties must be choosing the same number of women. Therefore, if $W_{0}<W_{1}$ it must

\footnotetext{
${ }^{27}$ Notice that the voter located in $\bar{x}_{0}$ is indifferent between voting party 0 and abstaining before the increase in utility. If the utility of every voter increases by $\delta$, then the voter that is indifferent between voting party 0 and abstaining is now locacted in $\bar{x}_{0}+2 \delta / t$, as $u\left(\bar{x}_{0}+2 \delta / t, 0\right)+\delta=u\left(\bar{x}_{0}, 0\right)=\underline{u}$. Similarly, the voter located in $\bar{x}_{1}-2 \delta / t$ is indifferent between voting party 1 and abstaining after the increase in utility. Moreover, because $V_{0}+V_{1}+4 \frac{\delta}{t} \leq 1$, these voters (weakly) prefers to vote for parties 0 and 1 , respectively, than voting for the other party. Therefore, such a change in utility increases both parties votes by $2 \delta / t$.
} 
be because some voters abstain, and the marginal voters of the two parties differ. Moreover, it must also be the case that $d_{v}\left(\bar{x}_{0}\right)>d_{v}\left(\bar{x}_{1}\right)$. Because $d_{v}$ is monotonic, it must therefore be decreasing.

We show next that, for all voters $x \in[0,1], u(x, 0)$ decreases more than $u(x, 1)$ after the introduction of the female quota, i.e. $\Delta u(x, 0) \leq \Delta u(x, 1)$. To see this, notice that $\Delta u(x, p)=\Delta A_{p}-d_{v}(x) \cdot \Delta W_{p}$. The change in utility $\Delta u(x, p)$ is decreasing in $d_{v}(x)$. As $d_{v}(x)$ is decreasing in $x$, it follows that $\Delta u(x, 0)<\Delta u\left(\bar{x}_{0}, 0\right)$ for all $x<\bar{x}_{0}$, and $\Delta u(x, 1)>\Delta u\left(\bar{x}_{1}, 1\right)$ for all $x>\bar{x}_{1}$.

Define the function $\Psi\left(d_{v}\right)=\int_{\underline{a}_{w}^{q}}^{\underline{a}_{w}} a f_{w}(a) d a-\int_{\underline{a}_{m}}^{\underline{a}_{m}^{q}} a f_{m}(a) d a-d_{v} \int_{\underline{a}_{w}}^{\underline{a}_{w}^{q}} f(a) d a$, where $1-F\left(\underline{a}_{w}\right)-F\left(\underline{a}_{m}\right)=1-F\left(\underline{a}_{w}^{q}\right)-F\left(\underline{a}_{m}^{q}\right)=0,1-F\left(\underline{a}_{w}^{q}\right)=\underline{W}$, and $\underline{a}_{w}-\underline{a}_{m}=d_{v}$. It is easy to see that $\Psi\left(d_{v}\left(\bar{x}_{p}\right)\right)=\Delta u\left(\bar{x}_{p}, p\right)$. This means that $\Psi\left(d_{v}\left(\bar{x}_{p}\right)\right)$ measures the change in utility of party $p$ 's marginal voter after the introduction of quotas. If we differentiate with respect to $d_{v}$ we obtain:

$$
\begin{aligned}
\frac{\partial \Psi}{\partial d_{v}} & =\underline{a}_{w} f\left(\underline{a}_{w}\right) \frac{\partial \underline{a}_{w}}{\partial d_{v}}+\underline{a}_{m} f\left(\underline{a}_{m}\right) \frac{\partial \underline{a}_{m}}{\partial d_{v}}-d_{v} f\left(\underline{a}_{w}\right) \frac{\partial \underline{a}_{w}}{\partial d_{v}}-\int_{\underline{a}_{w}}^{\underline{a}_{w}^{q}} f(a) d a \\
& =-\int_{\underline{a}_{w}}^{\underline{a}_{w}^{q}} f(a) d a .
\end{aligned}
$$

The equality in the second line follows from the fact that $\underline{a}_{w}-\underline{a}_{m}=d_{v}, \frac{\partial \underline{a}_{w}}{\partial d_{v}}=1+\frac{\partial \underline{a}_{m}}{\partial d_{v}}$, and $\left[f\left(\underline{a}_{w}\right)+f\left(\underline{a}_{m}\right)\right] \frac{\partial \underline{a}_{w}}{\partial d_{v}}=f\left(\underline{a}_{m}\right) \cdot{ }^{28}$ Combining all these elements, we obtain $\underline{a}_{w} f\left(\underline{a}_{w}\right) \frac{\partial \underline{a}_{w}}{\partial d_{v}}+$ $\underline{a}_{m} f\left(\underline{a}_{m}\right) \frac{\partial \underline{a}_{m}}{\partial d_{v}}=d_{v} f\left(\underline{a}_{w}\right) \frac{\partial \underline{a}_{w}}{\partial d_{v}}$. Finally, notice that $\frac{\partial \Psi}{\partial d_{v}}<0$ whenever $\underline{a}_{w}<\underline{a}_{w}^{q}$ (as is the case for any $\left.d_{v} \in\left[d_{v}\left(\bar{x}_{1}\right), d_{v}\left(\bar{x}_{0}\right)\right]\right)$.

Since $\Psi$ is a decreasing function of $d_{v}$, and $d_{v}\left(\bar{x}_{0}\right)>d_{v}\left(\bar{x}_{1}\right)$, it immediately follows that $\Delta u\left(\bar{x}_{0}, 0\right)<\Delta u\left(\bar{x}_{1}, 1\right)<0$. Moreover, because $\Delta u(x, 0)<\Delta u\left(\bar{x}_{0}, 0\right)$ for all $x<\bar{x}_{0}$, and $\Delta u(x, 1)>\Delta u\left(\bar{x}_{1}, 1\right)$ for all $x>\bar{x}_{1}$, we must have $\Delta V_{0}<\Delta V_{1}<0$.

Proof of proposition 3. Notice that $W_{0}<W_{1}<\frac{1}{2}$ implies that $F_{0 w}\left(\underline{a}_{0 w}\right)>F_{1 w}\left(\underline{a}_{1 w}\right)$ and $F_{0 m}\left(\underline{a}_{0 w}\right)<F_{1 m}\left(\underline{a}_{1 w}\right)$. By the assumption that $F_{p g}(a)=F_{g}\left(a-a_{p g}\right)$, it follows that $\underline{a}_{0 w}-$ $a_{0 w}>\underline{a}_{1 w}-a_{1 w}$ and $\underline{a}_{0 m}-a_{0 m}<\underline{a}_{1 m}-a_{1 m}$. Moreover, because $d_{v}=d_{0}=d_{1}=0$, parties do not discriminate against women in the absence of quotas, and they both set $\underline{a}_{p w}=\underline{a}_{p m}$. It also follows that $\Delta u(x, p)=\Delta A_{p}$.

The marginal man and woman of a given party have the same ability. The introduction of the quota therefore forces parties to set $\underline{a}_{p w}^{q}<\underline{a}_{p m}^{q}$. Moreover, since both parties end up with the same number of women under the quotas, it must be the case that $\underline{a}_{0 g}^{q}-a_{0 g}=\underline{a}_{1 g}^{q}-a_{1 g}$

\footnotetext{
${ }^{28}$ The last equality follows from differentiating the equation $1-F\left(\underline{a}_{w}\right)-F\left(\underline{a}_{m}\right)=0$ with respect to $d_{v}$, and substituting $\frac{\partial \underline{a}_{m}}{\partial d_{v}}=\frac{\partial \underline{a}_{w}}{\partial d_{v}}-1$.
} 
for both $g \in\{m, w\}$. As before, we have that:

$$
\Delta A_{p}=\int_{\underline{\underline{a}}_{p w}^{q}}^{\underline{a}_{p w}} a f_{p w}(a) d a-\int_{\underline{\underline{a}}_{p m}}^{\underline{a}_{p m}^{q}} a f_{p m}(a) d a .
$$

Notice that because $\underline{a}_{p w}^{q}<\underline{a}_{p w}=\underline{a}_{p m}<\underline{a}_{p m}^{q}, \Delta A_{p}<0$ and therefore so is $\Delta u(x, p)$. Furthermore, we can write

$$
\begin{aligned}
\Delta A_{0} & =\int_{\underline{a}_{0 w}^{q}}^{\underline{a}_{0 w}} a f_{w}\left(a-a_{0 w}\right) d a-\int_{\underline{a}_{0 m}}^{a_{0 m}^{q}} a f_{m}\left(a-a_{0 m}\right) d a=\int_{\underline{a}_{0 w}^{q}-a_{0 w}}^{\underline{a}_{0 w}-a_{0 w}} a f_{w}(a) d a-\int_{\underline{a}_{0 m}-a_{0 m}}^{a_{0 m}^{q}-a_{0 m}} a f_{m}(a) d a \\
& =\Delta A_{1}+\int_{\underline{a}_{1 w}-a_{1 w}}^{\underline{a}_{0 w}-a_{0 w}} a f_{w}(a) d a-\int_{\underline{a}_{0 m}-a_{0 m}}^{\underline{a}_{1 m}-a_{1 m}} a f_{m}(a) d a \\
& =\Delta A_{1}+\int_{\underline{a}_{1 w}-a_{1 w}+a_{0 w}}^{\underline{a}_{0 w}} a f_{w}\left(a-a_{0 w}\right) d a-\int_{\underline{a}_{0 m}}^{\underline{a}_{1 m}-a_{1 m}+a_{0 m}} a f_{m}\left(a-a_{0 m}\right) d a \\
& \leq \Delta A_{1}+\underline{a}_{0 w}\left[F_{w}\left(\underline{a}_{0 w}-a_{0 w}\right)-F_{w}\left(\underline{a}_{1 w}-a_{1 w}\right)\right]-\underline{a}_{0 m}\left[F_{m}\left(\underline{a}_{1 m}-a_{1 m}\right)-F_{m}\left(\underline{a}_{0 m}-a_{0 m}\right)\right] \\
& =\Delta A_{1},
\end{aligned}
$$

where the inequality follows from the fact that $F_{w}\left(\underline{a}_{0 w}-a_{0 w}\right)-F_{w}\left(\underline{a}_{1 w}-a_{1 w}\right)=F_{m}\left(\underline{a}_{1 m}-a_{1 m}\right)-$ $F_{m}\left(\underline{a}_{0 m}-a_{0 m}\right)$.

Since the utility from voting either party decreases, turnout cannot increase. Indeed, if turnout is less than $100 \%$ without quotas, it must decrease after the quotas are introduced.

Denote by $V_{p}^{q}$ and $V_{p}$ the number of voters voting for party $p$ with and without quotas, respectively. We also need to see that $\Delta V_{0}<\Delta V_{1}$. If there is full participation with quotas, then there is also full participation without quotas. The marginal voter, located at $x=\bar{x}_{0}$ is indifferent between the two parties when no quota is present. However, because $\Delta u(x, 0)<\Delta u(x, 1)$, this voter must strictly prefer to vote for party 1 when quotas are introduced. As a result, $\Delta V_{0}<0<\Delta V_{1}$.

When there is a partial turnout under quotas we have $V_{0}^{q}+V_{1}^{q}<1$. If the absence of quotas does not lead to full participation either, then $\Delta V_{p}=2 \Delta A_{p} / t$, because transportation costs are linear and voters are uniformly distributed on the line. It is immediate that $\Delta V_{0}<\Delta V_{1}$. Instead, if the absence of quotas result in full participation, we can decrease the utility from voting each party in two steps. First, decrease the utility of voting party $p$ for voter $x$ by adding $\delta_{p}^{1}=\max \left\{\Delta A_{0}, \underline{u}-u\left(\bar{x}_{0}, 0\right)\right\}$ to $u(x, p)$. (Notice that the marginal voter $\bar{x}_{0}$ is indifferent between voting either of the two parties, and therefore, $\underline{u}-u\left(\bar{x}_{0}, 0\right)=$ $\underline{u}-u\left(\bar{x}_{0}, 1\right)$.) In the second step we decrease the utility $u(x, p)$ by adding $\delta_{p}^{2}=\Delta A_{p}-$ $\max \left\{\Delta A_{0}, \underline{u}-u\left(\bar{x}_{0}, 0\right)\right\}$. Notice that after the two steps the utility of voting for party $p$ decrease by $\Delta A_{p}$ (the full decrease caused by the female quota). The decrease in the first 
step is common to both parties. Moreover, it still leads to full participation, as all voters still prefer to vote for one of the two parties rather than abstaining. As a result, since the utility of the marginal voter from voting each of the parties drops by the same amount, this voter is still indifferent between them. Hence, $V_{0}$ and $V_{1}$ remain unchanged. The drop in utility in the second step is larger for party 0 than for party 1 . Moreover, either the utility of voting for party 1 does not decrease in the second step (if $\Delta A_{1} \geq \underline{u}-u\left(\bar{x}_{0}, 0\right)$ ), or the marginal voter $\bar{x}_{0}$ is indifferent between voting either party or abstaining (if $\Delta A_{1}<\underline{u}-u\left(\bar{x}_{0}, 0\right)$ ). In either case, $V_{0}$ decreases by more than $V_{1}$ in this second step (notice that in the second case $V_{p}$ decreases by $\left.2 \delta_{p}^{2} / t\right)$. Therefore, adding the effects of the two steps, we get that $\Delta V_{0}<\Delta V_{1}$. 
TABLE 1

Quota's Impact: Number of Lists by Number of Women Candidates




TABLE 2

Impact of Equality Law on Women's Political Activism

\begin{tabular}{|c|c|c|c|c|c|c|}
\hline & \multicolumn{5}{|c|}{ Share of Women in Municipal Lists } & \multirow[t]{2}{*}{$\begin{array}{c}\text { Share of Elected } \\
\text { Women }\end{array}$} \\
\hline & \multicolumn{4}{|c|}{ All Positions in List } & \multirow{2}{*}{$\begin{array}{c}\text { Top } 5 \\
\text { (5) }\end{array}$} & \\
\hline & (1) & (2) & $\begin{array}{l}\text { Placebo } \\
\text { (3) }\end{array}$ & (4) & & (6) \\
\hline Equality Law Binds x 2007 & $\begin{array}{c}0.072 \\
(0.015)^{\star \star \star}\end{array}$ & $\begin{array}{c}0.076 \\
(0.015)^{\star \star \star}\end{array}$ & $\begin{array}{c}0.000 \\
(0.017)\end{array}$ & $\begin{array}{c}0.086 \\
(0.005)^{\star \star \star}\end{array}$ & $\begin{array}{c}0.083 \\
(0.007)^{\star \star \star}\end{array}$ & $\begin{array}{c}0.043 \\
(0.008)^{\star \star \star}\end{array}$ \\
\hline Year 2007 & & & & $\begin{array}{c}0.048 \\
(0.003)^{\star \star \star}\end{array}$ & $\begin{array}{c}0.047 \\
(0.004)^{\star \star \star}\end{array}$ & $\begin{array}{c}0.05 \\
(0.004)^{\star \star \star}\end{array}$ \\
\hline $\begin{array}{l}\text { Two-sided Population Polinomials in } \\
\text { Distance to Discontinuity }\end{array}$ & Y) & Yes & Y) & Y) & Yes & Yac \\
\hline FE & None & Province & Province & Municipality & Municipality & Municipality \\
\hline Years & 2007 & 2007 & 2003 & $2003-2007$ & 2003-2007 & $2003-2007$ \\
\hline Observations (Municipality by Year) & 1438 & 1438 & 1400 & 2874 & 2874 & 2874 \\
\hline Number of Municipalities & 1438 & 1438 & 1400 & 1437 & 1437 & 1437 \\
\hline R-squared & 0.33 & 0.41 & 0.24 & 0.52 & 0.37 & 0.23 \\
\hline
\end{tabular}

Standard errors in parentheses

* significant at 10\%; ** significant at 5\%; *** significant at 1\% 


\section{TABLE 3 \\ Female Quotas Do not Impede Local List Formation}

\begin{tabular}{|c|c|c|c|}
\hline \multirow[b]{2}{*}{ Equality Law Dummy } & \multicolumn{2}{|c|}{$\begin{array}{l}2003 \text { List Missing in } 2007 \\
\text { (yes }=1, \text { no=0) }\end{array}$} & \multirow{2}{*}{$\begin{array}{c}\begin{array}{c}\text { New List in } 2007 \\
\text { (yes=1, no=0) }\end{array} \\
\begin{array}{c}0.021 \\
(0.031)\end{array}\end{array}$} \\
\hline & $\begin{array}{c}0.010 \\
(0.027)\end{array}$ & & \\
\hline $\begin{array}{l}\text { Max }\{0, \text { Required Women in } 2007 \text { - Women in } 2003 \text { List }\} \text { x } \\
\text { Equality Law Dummy }\end{array}$ & & $\begin{array}{l}-0.006 \\
(0.007)\end{array}$ & \\
\hline Women in List 2003 & $\begin{array}{c}0.001 \\
(0.002)\end{array}$ & $\begin{array}{l}-0.001 \\
(0.003)\end{array}$ & $\begin{array}{c}0.000 \\
(0.003)\end{array}$ \\
\hline Share of Vote in 2003 (columns 1 and 2) or 2007 (column 3) & $\begin{array}{c}-0.174 \\
(0.016)^{\star \star \star}\end{array}$ & $\begin{array}{l}-0.159 \\
(0.022)^{\star \star \star}\end{array}$ & $\begin{array}{l}-0.229 \\
(0.021)^{\star \star \star}\end{array}$ \\
\hline Party Fixed Effects & yes & yes & yes \\
\hline Municipal Fixed Effects & no & yes & no \\
\hline Two-sided Population Polinomials in Distance to Discontinuity & yes & no & yes \\
\hline $\begin{array}{l}\text { Observations (Lists in } 2003 \text { - columns } 1 \text { and 2; Lists in } 2007 \text { - } \\
\text { column 3) } \\
\text { R-squared }\end{array}$ & $\begin{array}{l}5289 \\
0.71\end{array}$ & $\begin{array}{c}5289 \\
0.78\end{array}$ & $\begin{array}{l}5678 \\
0.69\end{array}$ \\
\hline
\end{tabular}

Standard errors in parentheses (clustered at the municipal level)

* significant at $10 \%$; ** significant at $5 \%$; *** significant at $1 \%$ 
TABLE 4

Female Quotas: Effects on Female Candidate Retention, Promotion, or New Arrivals

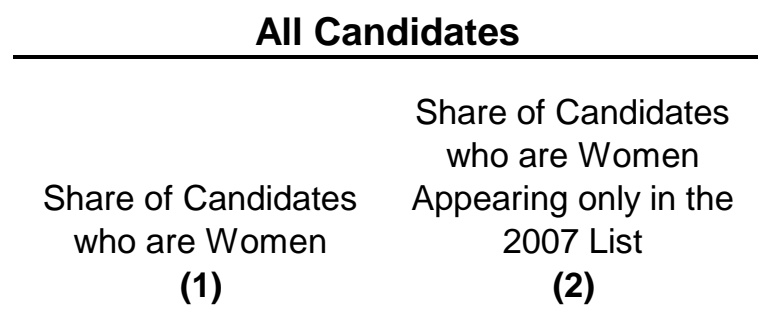

Equality Law x 2007

Two-sided Population Polinomials in Distance to Discontinuity

Municipal and Year Fixed Effects

Observations (All Individuals in all Lists and relevant municipality, by year)

Sample (Years)

Number of municipalities

R-squared

Standard errors in parentheses

* significant at 10\%; ** significant at 5\%; *** significant at $1 \%$

\section{Only Candidates in Top 5 Positions}

Share of Candidates

who are Women

Share of Candidates who are Women

(3)

Appearing only in the 2007 List

(4)

$\begin{array}{cc}0.08 & 0.065 \\ (0.011)^{\star \star \star} & (0.009)^{\star \star \star}\end{array}$

$(0.006)^{\star \star \star}$

yes

yes

yes

yes

yes

yes

125676

125676

54614

54614

2003 and 2007

2003 and 2007

1438

2003 and 2007

1438

0.01

0.01

2003 and 2007

1438

0.01 
TABLE 5

\section{Impact of a Female 40\% Quota on Measures of Voter Participation}

\begin{tabular}{|c|c|c|c|c|c|}
\hline & \multicolumn{4}{|c|}{ Voter Participation Rate } & $\begin{array}{c}\text { Share of Blank and Null } \\
\text { Votes }\end{array}$ \\
\hline & $\begin{array}{l}\text { OLS } \\
(1)\end{array}$ & \multicolumn{3}{|c|}{$\begin{array}{l}\text { Town Fixed Effects + IV } \\
\text { (3) }\end{array}$} & $\begin{array}{l}\text { Town Fixed Effects + IV } \\
\text { (5) }\end{array}$ \\
\hline Share of Women Candidates & $\begin{array}{c}0.145 \\
(0.024)^{\star \star \star}\end{array}$ & $\begin{array}{l}-0.008 \\
(0.044)\end{array}$ & $\begin{array}{l}-0.019 \\
(0.031)\end{array}$ & $\begin{array}{l}-0.024 \\
(0.046)\end{array}$ & $\begin{array}{c}-0.02 \\
(0.028)\end{array}$ \\
\hline Year 2007 & $\begin{array}{c}-0.035 \\
(0.002)^{\star \star \star}\end{array}$ & $\begin{array}{c}-0.019 \\
(0.003)^{\star \star \star}\end{array}$ & $\begin{array}{c}-0.018 \\
(0.003)^{\star \star \star}\end{array}$ & $\begin{array}{l}-0.017 \\
(0.007)^{\star \star}\end{array}$ & $\begin{array}{c}0.001 \\
(0.002)\end{array}$ \\
\hline Instruments & None & $\begin{array}{l}\text { Inequality Law } \\
\text { Binding } \times 2007\end{array}$ & \multicolumn{2}{|c|}{$\begin{array}{l}\text { Inequality Law Binding x } 2007 \times \\
\text { Distance to 40\% Target in } 2003\end{array}$} & \begin{tabular}{|c|} 
Inequality Law Binding $x$ \\
2007
\end{tabular} \\
\hline Number of Municipalities & 1,437 & 1,437 & 1,437 & $\begin{array}{c}421 \\
\text { (Treated Only) } \\
\end{array}$ & 1,437 \\
\hline Municipality FE & No & \multicolumn{3}{|c|}{ Yes } & Yes \\
\hline $\begin{array}{l}\text { Two-sided Population Polinomials in } \\
\text { Distance to Discontinuity }\end{array}$ & \multicolumn{5}{|c|}{ Yes } \\
\hline Years & \multicolumn{5}{|c|}{$2003-2007$} \\
\hline
\end{tabular}

\footnotetext{
Standard errors in parentheses

* significant at 10\%; ** significant at $5 \%$; ${ }^{\star \star *}$ significant at $1 \%$
} 
TABLE 6

Effects of Female Quotas: Positive Impact of Women On Electoral Results

\begin{tabular}{|c|c|c|c|c|c|c|c|}
\hline & \multicolumn{7}{|c|}{ 2007-2003 Change in Share of the Vote for Party } \\
\hline & (1) & (2) & (3) & (4) & (5) & (6) & (7) \\
\hline Change in Number of Women in List (Instrumented) & $\begin{array}{c}0.007 \\
(0.003)^{\star \star}\end{array}$ & $\begin{array}{c}0.01 \\
(0.003)^{\star \star \star}\end{array}$ & $\begin{array}{c}0.024 \\
(0.013)^{\star}\end{array}$ & $\begin{array}{c}0.01 \\
(0.003)^{\star \star \star}\end{array}$ & $\begin{array}{c}0.009 \\
(0.003)^{\star \star \star}\end{array}$ & $\begin{array}{c}0.016 \\
(0.005)^{\star \star \star}\end{array}$ & $\begin{array}{c}0.004 \\
(0.005)\end{array}$ \\
\hline Number of Women in List in 2003 & & & $\begin{array}{c}0.014 \\
(0.010)\end{array}$ & & & & \\
\hline Share of Candidates Repeating from 2003 List & & & & $\begin{array}{l}-0.013 \\
(0.012)\end{array}$ & $\begin{array}{c}0.054 \\
(0.012)^{\star \star \star}\end{array}$ & & \\
\hline List Won 2003 Election & & & & & $\begin{array}{c}-0.059 \\
(0.004)^{\star \star \star}\end{array}$ & & \\
\hline Observations (Lists by Municipality in 2007) & 1329 & 4191 & 4191 & 4191 & 4191 & 1491 & 2700 \\
\hline \multicolumn{8}{|l|}{ R-squared } \\
\hline Municipality Fixed Effects & yes & yes & yes & yes & yes & yes & yes \\
\hline Party Fixed Effects & yes & yes & yes & yes & yes & yes & yes \\
\hline Sample (Population Size) & $5000-8000$ & & & & $2000-8000$ & & \\
\hline Instrument & $\operatorname{Max}\{0,1$ & Required $W$ & men in 20 & 07 - Wome & $n$ in $2003 \mathrm{~L}$ & ist $\} \times$ Equality Law & Dummy \\
\hline Weights & & & Part & ty Vote Sha & are in 2003 & & \\
\hline Sample & Only Treated & & II Treated & and Control & & $\begin{array}{l}\text { Non-Competitive } \\
\text { Elections }\end{array}$ & $\begin{array}{c}\text { Competitive } \\
\text { Elections }\end{array}$ \\
\hline
\end{tabular}

Standard errors in parentheses

* significant at $10 \%$; ** significant at $5 \%$; *** significant at $1 \%$

All regressions include municipality and National-Party fixed effects. 


\section{TABLE 7 \\ Electoral Competition and Share of Women: Pre-Quota}

\begin{tabular}{|c|c|c|c|}
\hline & $\begin{array}{l}\text { Women's Share } \\
\text { in } 2003\end{array}$ & \multicolumn{2}{|c|}{$\begin{array}{c}\text { Women's Share 2003: } \\
\text { Top } 5 \text { Positions }\end{array}$} \\
\hline & (1) & $(2)$ & (3) \\
\hline Non-competitive Town in 2003 & $\begin{array}{l}-0.062 \\
(0.060)\end{array}$ & $\begin{array}{c}-0.012 \\
(0.007)^{\star}\end{array}$ & $\begin{array}{c}0.008 \\
(0.007)\end{array}$ \\
\hline Non-competitive Town x List Won the 2003 Election & & & $\begin{array}{c}-0.033 \\
(0.011)^{\star \star \star}\end{array}$ \\
\hline List won the 2003 Election & & & $\begin{array}{l}-0.001 \\
(0.006)\end{array}$ \\
\hline R-squared & 0.08 & 0.01 & 0.01 \\
\hline Sample (Year) & \multicolumn{3}{|c|}{2003} \\
\hline Sample (Population Size) & \multicolumn{3}{|c|}{$2000-8000$} \\
\hline Two-sided Population Polinomials & \multicolumn{3}{|c|}{ Yes } \\
\hline Weights & \multicolumn{3}{|c|}{ Party Vote Share in 2003} \\
\hline Observations (Lists in Municipalities in 2003) & \multicolumn{3}{|c|}{5281} \\
\hline
\end{tabular}

Robust standard errors in parentheses (clustered at the municipality level)

* significant at 10\%; ** significant at 5\%; ${ }^{* * *}$ significant at $1 \%$ 
TABLE 8

Women Leveraged Bargaining Power from Quota

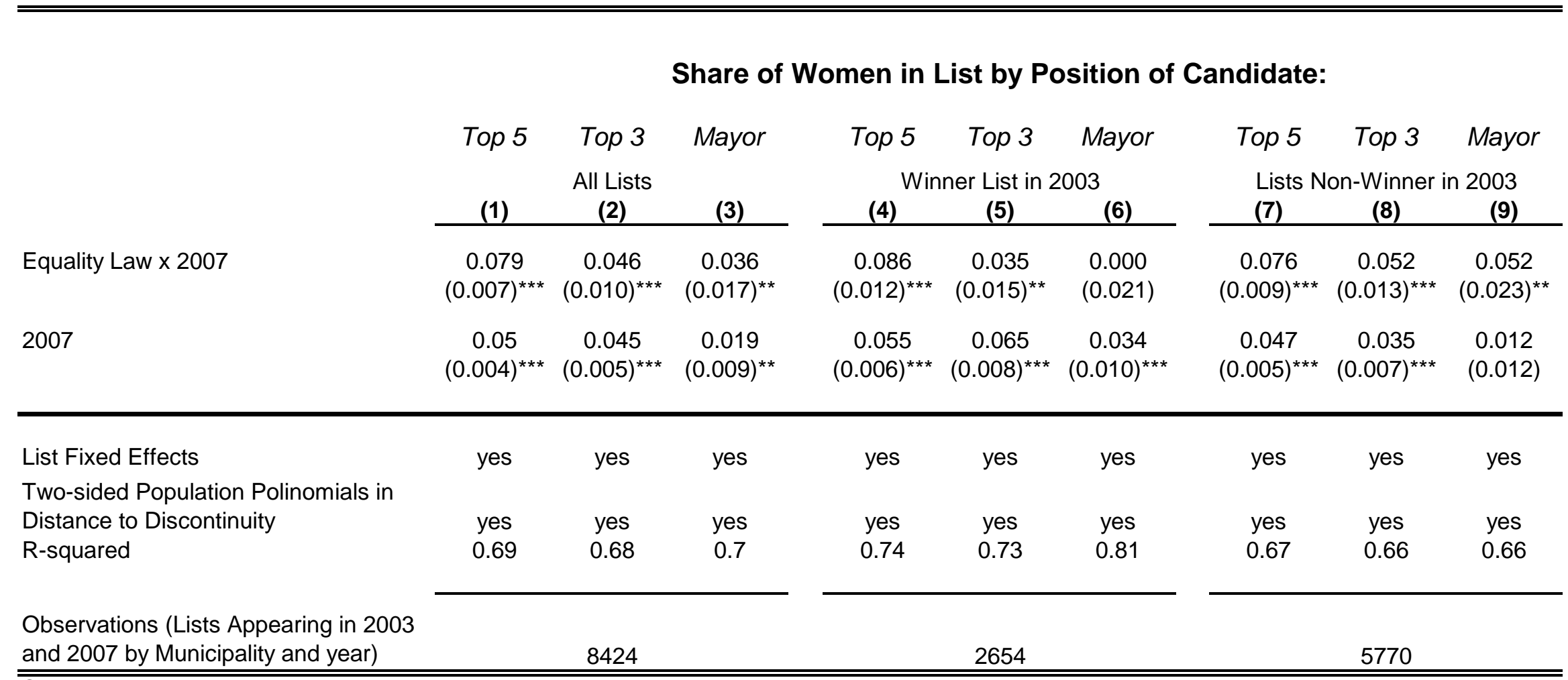

Standard errors in parentheses

* significant at 10\%; ** significant at 5\%; *** significant at $1 \%$ 
TABLE 9

Quotas Did not Increase Presence of High-Status Names

Panel A: Highest and Lowest Power-Status Female Names, and Common Surnames

(1)

\begin{tabular}{lc}
\hline High-Status First Names & $\begin{array}{c}\text { Electability } \\
\text { in } 2003 \\
\text { Relative to } \\
\text { Mean }\end{array}$ \\
IZASKUN & 2.20 \\
IDOIA & 2.13 \\
VIRTUDES & 1.91 \\
MIREN & 1.81 \\
ALFONSA & 1.76 \\
REYES & 1.70 \\
MAITE & 1.59 \\
AMAIA & 1.57 \\
AGUSTINA & 1.56 \\
AINHOA & 1.53 \\
MONTSE & 1.53 \\
TRINIDAD & 1.46 \\
CANDELARIA & 1.42 \\
ESMERALDA & 1.39 \\
DULCE & 1.37 \\
CONCEPCIO & 1.35 \\
BENITA & 1.35 \\
MARGARIDA & 1.35 \\
EMMA & 1.34 \\
RITA & 1.33 \\
M &
\end{tabular}

(2)

\begin{tabular}{lc}
\hline Low-Status & $\begin{array}{c}\text { Electability } \\
\text { in } 2003 \\
\text { Relative to } \\
\text { First Names }\end{array}$ \\
Mean \\
TANIA & 0.15 \\
LAIA & 0.22 \\
LETICIA & 0.25 \\
TAMARA & 0.32 \\
LORENA & 0.34 \\
VANESSA & 0.36 \\
MACARENA & 0.42 \\
NOEMI & 0.42 \\
ESTER & 0.47 \\
ELISABET & 0.47 \\
GRACIA & 0.47 \\
MARCELINA & 0.49 \\
CONSOLACION & 0.49 \\
ELISABETH & 0.50 \\
VICTORIA & 0.50 \\
SABINA & 0.51 \\
MIREIA & 0.52 \\
SANDRA & 0.52 \\
PATROCINIO & 0.54 \\
ALBA & 0.55
\end{tabular}

(3)

\begin{tabular}{lc}
\multicolumn{2}{c}{ (3) } \\
\hline \\
Common & \\
Surnames & Percentage \\
& \\
GARCIA & $3.60 \%$ \\
FERNANDEZ & $2.27 \%$ \\
GONZALEZ & $2.18 \%$ \\
RODRIGUEZ & $2.11 \%$ \\
SANCHEZ & $1.98 \%$ \\
MARTINEZ & $1.88 \%$ \\
LOPEZ & $1.87 \%$ \\
PEREZ & $1.82 \%$ \\
MARTIN & $1.19 \%$ \\
GOMEZ & $1.11 \%$ \\
HERNANDEZ & $0.82 \%$ \\
RUIZ & $0.81 \%$ \\
JIMENEZ & $0.76 \%$ \\
DIAZ & $0.74 \%$ \\
ALVAREZ & $0.71 \%$ \\
MORENO & $0.65 \%$ \\
MUÑOZ & $0.59 \%$ \\
Total & $25.08 \%$ \\
&
\end{tabular}

Panel B: Impact of Quotas on High-Status Females

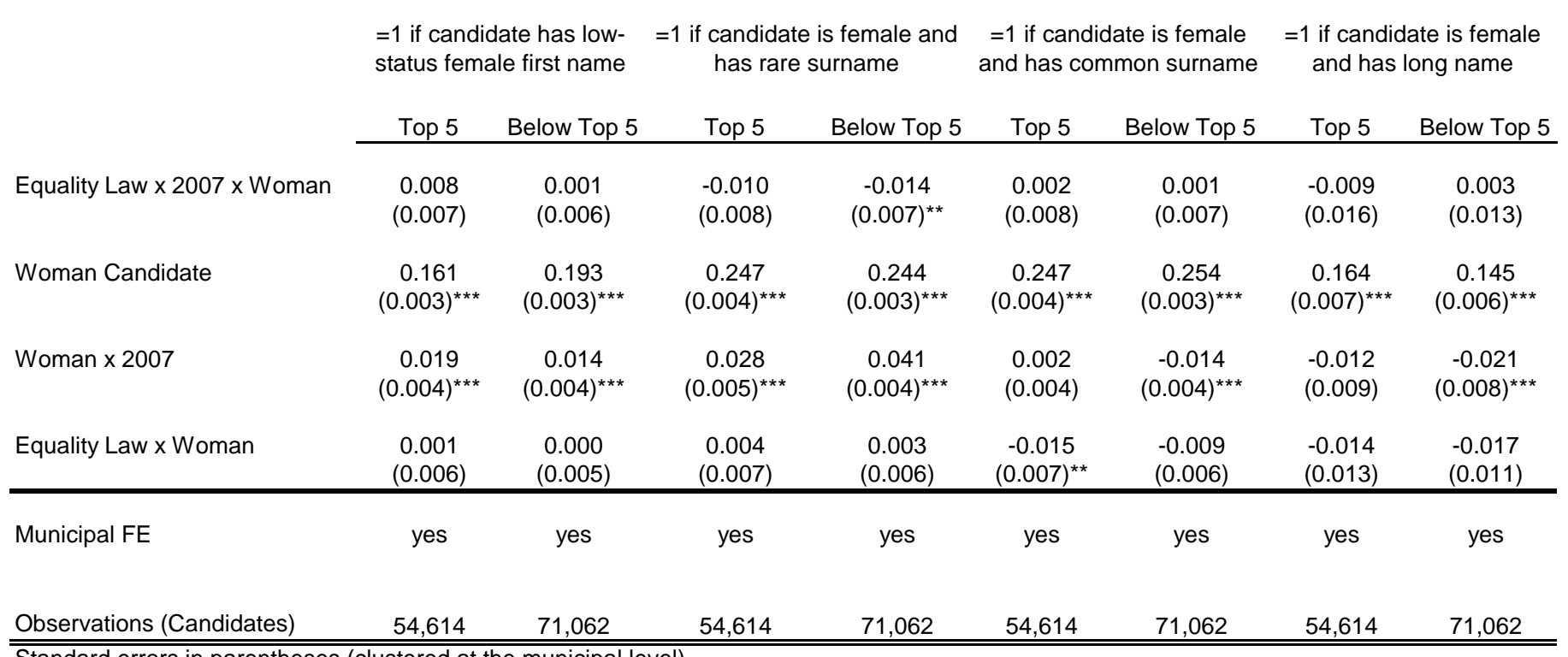




\section{Appendix TABLE 1}

\section{Impact of Equality Law Female Participation: Banwidth robustness}

\begin{tabular}{|c|c|c|c|c|c|c|c|c|c|}
\hline & \multicolumn{9}{|c|}{ Share of Women in Municipal Lists } \\
\hline & $(1)$ & $(2)$ & (3) & $(4)$ & $(5)$ & (6) & $(7)$ & (8) & $(9)$ \\
\hline Equality Law Binds x 2007 & $\begin{array}{c}0.089 \\
(0.006)^{\star \star \star}\end{array}$ & $\begin{array}{c}0.084 \\
(0.005)^{\star \star \star}\end{array}$ & $\begin{array}{c}0.083 \\
(0.005)^{\star \star \star}\end{array}$ & $\begin{array}{c}0.086 \\
(0.005)^{\star \star \star}\end{array}$ & $\begin{array}{c}0.087 \\
(0.007)^{\star \star \star}\end{array}$ & $\begin{array}{c}0.081 \\
(0.006)^{\star \star \star}\end{array}$ & $\begin{array}{c}0.086 \\
(0.007)^{\star \star \star}\end{array}$ & $\begin{array}{c}0.088 \\
(0.009)^{\star \star \star}\end{array}$ & $\begin{array}{c}0.09 \\
(0.013)^{\star \star \star}\end{array}$ \\
\hline Year 2007 & $\begin{array}{c}0.043 \\
(0.002)^{\star \star \star}\end{array}$ & $\begin{array}{c}0.047 \\
(0.002)^{\star \star \star}\end{array}$ & $\begin{array}{c}0.049 \\
(0.002)^{\star \star \star}\end{array}$ & $\begin{array}{c}0.048 \\
(0.003)^{\star \star \star}\end{array}$ & $\begin{array}{c}0.05 \\
(0.003)^{\star \star \star}\end{array}$ & $\begin{array}{c}0.055 \\
(0.004)^{\star \star \star}\end{array}$ & $\begin{array}{c}0.051 \\
(0.005)^{\star \star \star}\end{array}$ & $\begin{array}{c}0.049 \\
(0.006)^{\star \star \star}\end{array}$ & $\begin{array}{c}0.042 \\
(0.009)^{\star \star \star}\end{array}$ \\
\hline \multirow{7}{*}{$\begin{array}{l}\text { Municipalities (Population Size) } \\
\text { Observations } \\
\text { Number of Municipalities } \\
\text { R-squared } \\
\text { Polinomial in Distance to Discontinuity } \\
\text { FE } \\
\text { Years }\end{array}$} & 0 to 10000 & 1000 to 9000 & 1500 to 8500 & 2000 to 8000 & 2500 to 7500 & 3000 to 7000 & 3500 to 6500 & 4000 to 6000 & 4500 to 5500 \\
\hline & 9460 & 4888 & 3658 & 2872 & 1885 & 1591 & 1135 & 762 & 376 \\
\hline & 4742 & 2445 & 1830 & 1437 & 943 & 796 & 568 & 381 & 188 \\
\hline & 0.23 & 0.41 & 0.47 & 0.52 & 0.54 & 0.61 & 0.64 & 0.65 & 0.7 \\
\hline & \multicolumn{9}{|c|}{ Yes } \\
\hline & & & & & Municipality & & & & \\
\hline & & & & & 2003-2007 & & & & \\
\hline
\end{tabular}




\section{Appendix TABLE 2}

No Other Discontinuities at Inequality Law Binding Population Level

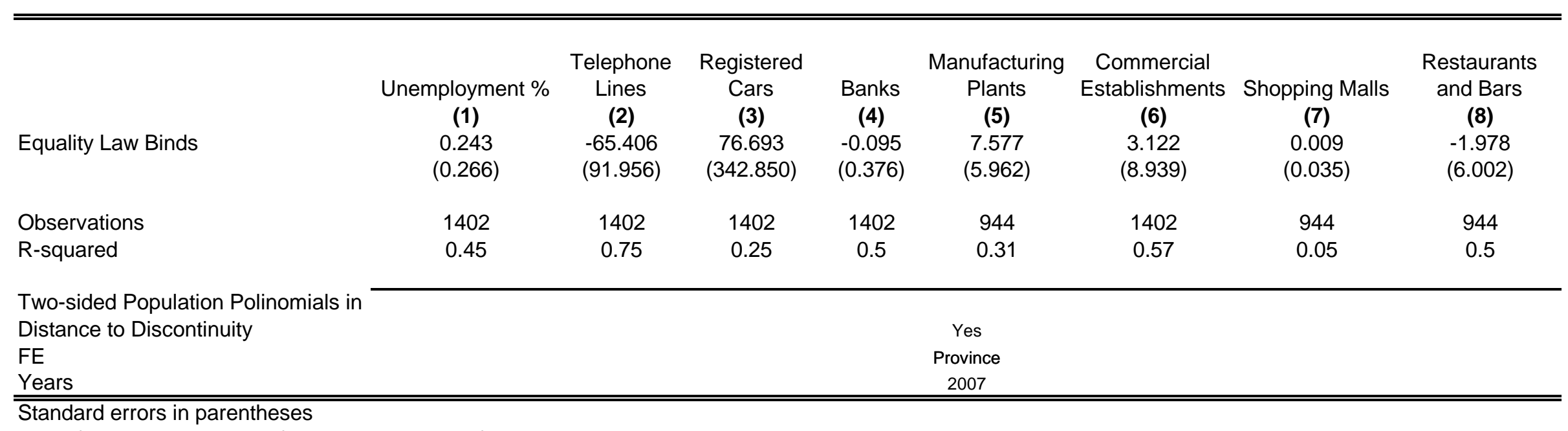

* significant at 10\%; ** significant at $5 \%$; $* * *$ significant at $1 \%$ 


\begin{tabular}{|c|c|c|c|}
\hline & \multicolumn{3}{|c|}{ Woman Candidate } \\
\hline & \multicolumn{2}{|c|}{ Elected } & \multirow{2}{*}{$\frac{\text { Low Status Name }}{\text { (3) }}$} \\
\hline & (1) & (2) & \\
\hline Low-Frequency Surname & $\begin{array}{c}0.006 \\
(0.004)\end{array}$ & $\begin{array}{c}0.014 \\
(0.004)^{\star \star \star}\end{array}$ & $\begin{array}{c}-0.015 \\
(0.004)^{\star \star \star}\end{array}$ \\
\hline Very Common Surname & $\begin{array}{c}-0.01 \\
(0.004)^{\star \star}\end{array}$ & $\begin{array}{c}-0.015 \\
(0.004)^{\star \star \star}\end{array}$ & $\begin{array}{c}0.011 \\
(0.004)^{\star \star \star}\end{array}$ \\
\hline Long Name & $\begin{array}{c}0.027 \\
(0.003)^{\star \star \star}\end{array}$ & $\begin{array}{c}0.025 \\
(0.003)^{\star \star \star}\end{array}$ & $\begin{array}{c}-0.114 \\
(0.003)^{\star \star \star}\end{array}$ \\
\hline Constant & $\begin{array}{c}0.205 \\
(0.003)^{\star \star \star} \\
\end{array}$ & $\begin{array}{c}0.21 \\
(0.005)^{\star \star \star} \\
\end{array}$ & $\begin{array}{c}0.331 \\
(0.003)^{\star \star \star} \\
\end{array}$ \\
\hline Region FE & No & Yes & Yes \\
\hline Year & 2003 & 2003 & 2003 and $2007^{\wedge}$ \\
\hline Observations & 70,556 & 70,556 & 98,941 \\
\hline R-squared & 0 & 0.02 & 0.02 \\
\hline
\end{tabular}

Robust standard errors in parentheses

* significant at 10\%; ** significant at 5\%; *** significant at $1 \%$

$\wedge$ Excludes Maria, which is very often used with another first name 